\title{
Implementation of a non-Hertzian Contact Model for Railway Dynamic Application
}

\author{
Hugo Magalhães ${ }^{1,2}$, Filipe Marques ${ }^{3}$, Binbin Liu ${ }^{4}$, Pedro Antunes ${ }^{1,2}$, João Pombo ${ }^{1,2,5}$, Paulo Flores ${ }^{3}$, \\ Jorge Ambrósio ${ }^{2}$, Jerzy Piotrowski ${ }^{6}$, Stefano Bruni ${ }^{4}$ \\ ${ }^{I}$ Institute of Railway Research, School of Computing and Engineering, University of Huddersfield, UK \\ \{h.magalhaes,j.pombo,p.antunes\}@hud.ac.uk \\ ${ }^{2}$ IDMEC, Instituto Superior Técnico, Universidade de Lisboa, Lisboa, Portugal, jorge.ambrosio@tecnico.ulisboa.pt \\ ${ }^{3}$ CMEMS-UMinho, Departamento de Engenharia Mecânica, Universidade do Minho, \\ Portugal, \{fmarques,pflores\}@dem.uminho.pt \\ ${ }^{4}$ Dipartimento di Meccanica, Politecnico di Milano, Italy, \{binbin.liu,stefano.bruni\}@polimi.it \\ ${ }^{5}$ ISEL, Intituto Politecnico de Lisboa, Lisboa, Portugal \\ ${ }^{6}$ Institute of Vehicles, Warsaw University of Technology,Poland, jpt@simr.pw.edu.pl
}

\begin{abstract}
The development of wheel-rail contact models is an active topic of railway research with the dual objective of improving the accuracy of multibody simulations and reducing its computational effort. This paper extends the online Hertzian contact model, proposed by Pombo et al.[1] to propose a non-Hertzian contact model. The new methodology presented here includes the following steps: (i) search of the points of contact; (ii) identification of the undeformed distance function; (iii) evaluation of the contact patch; (iv) calculation of the normal and tangential contact forces; (v) application of the contact forces in the multibody vehicle model. Among several contact models available in the literature, this non-Hertzian contact approach uses the Kik-Piotrowski model for the normal contact force, while the tangential forces are obtained from the interpolation of the available Kalker Book of Tables for Non-Hertzian (KBTNH) contact. With the purpose to demonstrate the proper implementation and selection of parameters that define this new model, several contact analysis and dynamic simulations are performed in which the wheel S1002 and the rail UIC50 are considered. First, the contact analyses that determine the contact condition of different wheel-rail interactions serve to assess the accuracy of the Hertzian and non-Hertzian models with respect to the software of reference CONTACT. Second, the Hertzian and nonHertzian models are utilized to perform dynamic simulations of a wheelset, a bogie and a vehicle running in tangent and curved tracks. In short, this work provides, not only a complete description of the implementation of a non-Hertzian contact model in a multibody code, but also suggests for the proper selection of the parameters that promote better accuracy and optimal computational efficiency.
\end{abstract}

\section{Nomenclature}

\begin{tabular}{|l|l|}
\hline$(.)_{\mathrm{cp}}$ & Subscript to identify the contact patch \\
\hline$(.)_{w}$ & Subscript to identify the wheelset $w$ \\
\hline$(.)_{\mathrm{r}}$ & Subscript to identify the rail \\
\hline$(.)^{\text {side }}$ & Superscript to identify the left and right side \\
\hline$a$ & Length of semi-axes of SDEC or elliptical contact patch in longitudinal direction \\
\hline$A$ & Curvature of the contact point in the lateral direction \\
\hline$A_{\mathrm{cp}}$ & Area of the contact patch \\
\hline
\end{tabular}




\begin{tabular}{|c|c|}
\hline $\mathbf{A}$ & Transformation matrix \\
\hline$b$ & Length of semi-axes of SDEC or elliptical contact patch in longitudinal direction \\
\hline b & Binormal vector \\
\hline$B$ & Curvature of the contact point in the longitudinal lateral \\
\hline d & Distant vector \\
\hline$D$ & Damping coefficient for the normal contact force \\
\hline$e$ & Restitution coefficient \\
\hline$E$ & Young Modulus \\
\hline$f_{\mathrm{r}}$ & Ordinate of the profile that represents the rail cross section \\
\hline$f_{w}$ & Ordinate of the profile that represents the wheelset $w$ cross section \\
\hline$f_{\mathrm{x}}$ & Normalized longitudinal creep force \\
\hline$f_{\mathrm{y}}$ & Normalized lateral creep force \\
\hline$F_{\mathrm{x}}$ & Longitudinal creep force \\
\hline$F_{\mathrm{y}}$ & Lateral creep force \\
\hline$g$ & Aspect ratio \\
\hline$g_{\text {und }}$ & Undeformed distance function \\
\hline g & External generalized forces vector \\
\hline$G$ & Shear Modulus \\
\hline $\mathrm{H}$ & Hertzian \\
\hline$H$ & Distance between the left and right wheel profiles \\
\hline$K$ & Contact stiffness \\
\hline KBTNH & Kalker Book of Tables for Non-Hertzian \\
\hline $\mathrm{L}$ & Left side \\
\hline$m_{\mathrm{z}}$ & Normalized creep moment \\
\hline$M_{\mathrm{z}}$ & Spin creep moment \\
\hline $\mathbf{M}$ & Mass matrix \\
\hline$n$ & Hertz nonlinear exponent \\
\hline $\mathbf{n}$ & Normal unit vector \\
\hline $\mathrm{NH}$ & Non-Hertzian \\
\hline$N$ & Normal force magnitude \\
\hline PS & Primary Suspension \\
\hline$P$ & Potential point of contact in the rail \\
\hline$p_{0}$ & Maximum normal pressure of the KP model \\
\hline$p_{\max }$ & Maximum normal pressure \\
\hline $\mathbf{q}$ & System generalized coordinates \\
\hline$Q$ & Potential point of contact in the wheel \\
\hline$r$ & Radial coordinate \\
\hline $\mathbf{r}$ & Position vector \\
\hline$S_{\mathrm{r}}$ & Arclength coordinate of the rail surface \\
\hline$s_{w}$ & Angular coordinate of the wheel surface \\
\hline SS & Secondary Suspension \\
\hline SDEC & Single Double Elliptical Contact \\
\hline $\mathrm{R}$ & Right side \\
\hline $\mathbf{v}$ & Velocity vector \\
\hline $\mathbf{t}$ & Tangential vector \\
\hline$u_{\mathrm{r}}$ & Lateral coordinate of the rail surface \\
\hline
\end{tabular}




\begin{tabular}{|c|c|}
\hline$u_{w}$ & Lateral coordinate of the wheel surface \\
\hline$x_{\mathrm{L}}$ & Length of the strip \\
\hline$x, y, z$ & Cartesian coordinates \\
\hline$y_{0}$ & One dimension of the SDEC \\
\hline$\alpha$ & Direction of the linear creepage \\
\hline$\gamma$ & Tangent angle of the cross-section \\
\hline$\gamma$ & Right-hand side of the acceleration constraint equations vector \\
\hline$\delta$ & Penetration magnitude \\
\hline$\dot{\delta}^{\max }$ & Maximum penetration velocity \\
\hline$\Delta F_{\mathrm{x}}$ & Deviation of the longitudinal creep force \\
\hline$\Delta F_{\mathrm{y}}$ & Deviation of the lateral creep force \\
\hline$\Delta M_{\mathrm{z}}$ & Deviation of the spin creep moment \\
\hline$\Delta r$ & Step size for the radial coordinate \\
\hline$\Delta s$ & Width of the strip \\
\hline$\Delta \theta$ & Step size for the angular coordinate \\
\hline$\varepsilon$ & Parameter that takes into account the existing deformation \\
\hline$\eta$ & Normalized lateral creepage \\
\hline$\theta$ & Angular coordinate \\
\hline$\kappa$ & Curvature \\
\hline$\lambda$ & Lagrange multipliers vector \\
\hline$\mu$ & Friction coefficient \\
\hline$v$ & Magnitude of the linear creepages \\
\hline$\xi$ & Normalized longitudinal creepage \\
\hline$\sigma$ & Poisson ratio \\
\hline$v_{\mathrm{x}}$ & Longitudinal creepage \\
\hline$v_{\mathrm{y}}$ & Lateral creepage \\
\hline$\varphi$ & Spin creepage \\
\hline $\boldsymbol{\Phi}_{q}$ & Jacobian matrix of the constraint equations \\
\hline$\chi$ & Normalized spin creepage \\
\hline$\psi$ & Shape factor of SDEC \\
\hline$\omega$ & Angular velocity vector \\
\hline
\end{tabular}

\section{Introduction}

In railway dynamics, the vehicle-track interaction has been studied mostly through multibody simulations where railway vehicles, running in tracks with realistic operation conditions, are analysed in a virtual environment [2]. By using these tools, virtual homologation [3-6], prediction of wear and rolling contact fatigue of wheels and rails [7-12], among other studies can be performed. A key ingredient in all these case studies is the wheel-rail contact model, which evaluates the contact reactions forces developed over the wheel-rail contacting area [13-19]. The calculation of these forces, in a multibody code, involves four steps, namely, $(i)$ identification of the contact patch, (ii) evaluation of the creepages, (iii) assessment of the normal and tangential contact forces in the wheel-rail interface, and (iv) application of the contact forces in the wheelsets and rails. Since the assessment of the wheel-rail contact is one of the most time-consuming processes in railway multibody simulations, the development of faster, yet accurate wheel-rail contact models is still a challenging and active topic of research [20-25]. The use of 'in-house' programs, in contrast to commercial software, has the advantage of allowing a complete control over of the implementation of the wheel-rail contact methodologies, hence allowing to adjust the simulation code to specific problems. However, even when the multibody 
formulation is established $[26,27]$ the implementation of the wheel-rail contact is still a complex task. Few works present complete formulations for the implementation of wheel-rail contact models in multibody codes [1, 28-33], being common the use of commercial software codes that are used even for benchmarking processes $[34,35]$. This work aims at presenting a new methodology for non-Hertzian contact models as well as its implementation in general multibody codes.

To perform a multibody simulation of a railway vehicle running in a track, the vehicle, track and vehicletrack interaction models are required. The multibody model of the vehicle consists of a set of bodies that are constrained by kinematic pairs and/or force elements that represent the suspension system of the vehicle [3638]. The track model is composed by two surfaces, representing the left and right rails, which control the motion of the wheels with the forces developed in the wheel-rail interfaces. The track modelling consists of a geometric parameterization problem where the rails positions and orientations are defined as function of selected parameters [39-41]. If the track flexibility is an important issue, the material and mechanical properties of the infrastructure must also be taken into account [42-45]. In turn, the wheel-rail contact model represents the interaction forces developed in the wheel-rail contact interface. The result of the simulation of a general railway dynamic problem includes the time history of vehicle kinematics and the forces developed in the multibody system, including the joint reaction and the wheel-rail contact forces.

The first step to solve the wheel-rail contact problem is the contact detection, when contact exists, the calculation of the wheel-rail contact patch which is generally considered non-conformal if it lies in a flat plane and treated as conformal when it lies in a curved surface. Several different approaches can be considered for the evaluation of the contact patch, which can be more or less accurate and computationally expensive. In any case, the parameterization of the wheel and rail profiles is always required. Due to the axial symmetry of the wheel, the revolution of its profile around its axis defines the wheel parametric surface, being the angle of revolution the first parameter while a second parameter is used to describe the transversal wheel profile. In turn, the rail surfaces are described as an extrusion of the rail cross-section, being the arc length of the sweep the first parameter while a second parameter defines the transversal rail profile. Thus, the contact detection problem can be solved as a constraint approach or as an elastic approach $[46,47]$. The constraint approach, used by some researchers to represent the wheel-rail contact, does not consider pseudo-penetration between the profiles, only allowing for one contact point per each wheel-rail pair [48, 49]. The unilateral constraint approach eliminates three relative degrees-of-freedom of the wheelset, being the contact points dependent on the longitudinal, lateral and yaw motions. In the elastic approach, two methods can be used, namely, the algebraic approaches $[1,28,50]$ and the nodal search method $[30,51,52]$. In the algebraic approach, normal and tangential vectors at the wheel and rail surfaces are defined to describe geometric constraints that define potential points of contact, where the minimum distance condition is imposed. In turn, the nodal search method is defined by discrete profiles where the penetration of each node of a profile inside the other profile is monitored and associated with a contact force. In any of the elastic approach, the six degrees-of-freedom of the wheelset are preserved. The resolution of the contact detection problem is one of the most time-consuming tasks in a multibody simulation. The use of lookup tables is a strategy to improve the computational efficiency by substituting the search by the interpolation of a table given the relative kinematics of the wheel and rail. This is mostly applied in constraint approaches [30, 48].

After the contact detection, the assessment of creepages is performed based on a kinematic analysis of the two contacting surfaces [1]. In this analysis, three creepages are typically considered, i.e., the longitudinal, lateral and spin creepages. While the longitudinal and lateral creepages are straightforward to understand, the spin creepage requires a more detailed description. The spin creepage consists of a rotation around the direction normal to the contacting area divided by the wheel's forward speed. Since the direction of the angular motion of the wheelset is not perpendicular to the normal of the contact area, spin creepages exist. Special emphasis is put in the flange contact, which occurs mainly in curve negotiations, where the spin creepage can increase significantly. In the case of a conformal contact, in which the contact slope varies considerably, large variations of the creepages over the contact area are expected [53-57]. 
The normal contact force developed in the wheel-rail interface results from the integral of the normal pressure distribution over the contacting area. Hertzian contact theory [58] has been widely used in multibody simulations due to its easiness of implementation and representativeness in a very wide number of contact conditions existing in engineering systems of interest. Among other conditions, this model assumes that the curvature at the contacting area is constant leading to an elliptical contact patch where a semi-ellipsoidal normal pressure distribution is considered. Due to the geometry of actual wheel and rail profiles, the Hertz model can be inaccurate for some wheel/rail pairs and relative wheel/rail portions. In these cases, a more accurate description is required. In this context, the CONTACT program [58], based on the Kalker rolling contact theory, uses much more refined rolling contact model providing results of reference. However, the online use of this program is too time-consuming to be applied in multibody simulations.

Contact models that consider virtual penetrations between wheel and rail have been proposed, being their accuracy compared with benchmark codes, such as CONTACT, or finite element methodologies [22, 24, 25, 5961]. These simplified models find the contact area as a portion of the interpenetration that is determined by the undeformed distance function, that is, the separation distance between the wheel and rail profiles. Numerical issues can arise during the implementation of such elastic contact models, such as, the numerical instability that can occur when considering multi-Hertzian contact, which leads to multiple elliptical contact patches, namely, in the case of overlapping contacts. This difficulty can easily be overcome by considering an equivalent and single Hertzian contact. However, this approach is not suitable to evaluate the distribution of pressure in the contact area. In turn, to simulate a wheelset running on a rigid track it is of crucial importance to include energy dissipation in the normal contact problem. For this purpose, Pombo et al. [1,28] proposed a modified version of the Hertzian contact model with hysteresis damping, known as the Lankarani-Nikravesh (LN) contact model $[62,63]$. This model uses the relative velocity between two surfaces and the restitution coefficient, not only to incorporate the energy dissipation that exists in the normal contact, but also to mitigate numerical instabilities when simulating wheelsets running on rigid tracks.

The tangential forces, namely, the longitudinal and lateral forces and spin moment, are of utmost importance for the lateral stability and longitudinal dynamics. Their calculation is typically based on the identification of the contact patch, creepages and normal contact force. An interesting comparison between different contact models used in multibody simulations has been presented by Vollebregt et al. [64], where the Kalker linear theory [65], Vermeulen-Johnson model [66], Shen-Hedrick-Elkins model [67], FASTIM [68], Polach model [69] and USETAB [70] are analysed and discussed against CONTACT. In their work, the VAMPIRE software has been used to perform dynamic simulations with realistic contact conditions, leading to the observation that FASTSIM and USETAB provide good results with respect to CONTACT, with root mean square differences in the range 5$10 \%$, while the other models exhibit higher deviation in the range of $15-60 \%$. More recently, a method named as FaStrip [71], which combines the FASTSIM and the stripe theory has been proposed. This method is an alternative to FASTSIM and requires a similar computational effort, while representing more accurately the slip velocity distribution. In this paper, particular attention is put in the USETAB that determines the creep forces by interpolating pre-calculated tables that have been generated by running CONTACT, considering different elliptical shapes and different creepages. Similarly, Piotrowski et al. propose the generation of the Kalker Book of Tables for Non-Hertzian contact (KBTNH) [20, 21]. This pre-calculated table is used to obtain creep forces and spin moment, being the non-Hertzian contact patch approximated to a Single-Double Elliptical Contact (SDEC) patch. With the intention of enhancing KBTNH, a new generation of the lookup table is proposed by Marques et al. [72]. Here, a detailed analysis of the interpolation error over the KBTNH has been presented either to reduce the refinement of the KBTNH, while maintaining appropriate accuracy, or to maintain the refinement while increasing accuracy. The interest on the KBTNH can be observed on a scientific discussion that is reported in [73] and [74], where Vollebregt and the authors of the KBTNH discuss the implications of considering the origin of the contact patch when defining the spin creepage.

This work presents the detailed formulation to implement a non-Hertzian contact method developed under the framework of multibody system methodologies. The 'in-house' multibody code used here, which follows the 
approach presented in [26], has been widely used not only in railway applications [4, 5, 28, 39, 75-77], but also to analyse other multibody mechanical systems [78]. The new non-Hertzian method can be understood as an extension of the Hertzian contact approach proposed by Pombo et al. [1, 28], with the addition of a strategy to determine the undeformed distance function to allow for the determination of non-elliptic contact patches. Among other contact models for non-Hertzian conditions, the Kik-Piotrowski (KP) model [59] and KBTNH [20, 21] are used to find the normal and tangential contact forces, respectively. Additionally, it is also proposed to add the dissipative term of the normal contact force of the LN model $[62,63]$ in the KP model with the intention of improving the realism of the simulations, namely, of a wheelset negotiating a rigid track. The proposed nonHertzian approach and the Hertzian contact model [1, 28], which is also briefly revisited here, have been compared with the software of reference CONTACT [58], considering different conditions for the wheel-rail interaction. Then, multibody simulations are performed for selected railway dynamic scenarios not only to demonstrate the effectiveness of the new wheel-rail contact method and the identification of appropriate parameters that lead to good results and faster simulations, but also to analyse the influence of the different modelling approaches of the wheel-rail contact presented in this work. The wheel and rail profiles S1002 and UIC50 are utilized since the contact developed is mainly elliptical, being the comparison between the Hertzian and non-Hertzian methods for this scenario done in the process.

\section{Multibody simulation}

The dynamic analysis of a multibody system involves the study of its motion and of the forces transmitted during a given time period, as a function of the initial and operation conditions. In railway applications, the vehicle model is defined by a set of bodies, such as, the carbody, bogie frame and wheelsets which are constrained by kinematic joints and force elements that represent the vehicle suspension system [5, 28, 42]. The track, considered in this work as a rigid system, is represented by two databases that describe the position and orientation of the left and right rails as a function of their arclength [39, 40]. The vehicle-track interaction is represented by forces developed in the wheel-rail contacting surfaces which are obtained from the wheel-rail contact module [1] described by the five tasks included in Fig. 1. The inputs for the wheel-rail contact are the states of the wheelsets being the force vectors and respective points of application the outputs of the analysis. A detailed description of these tasks is presented throughout this paper.

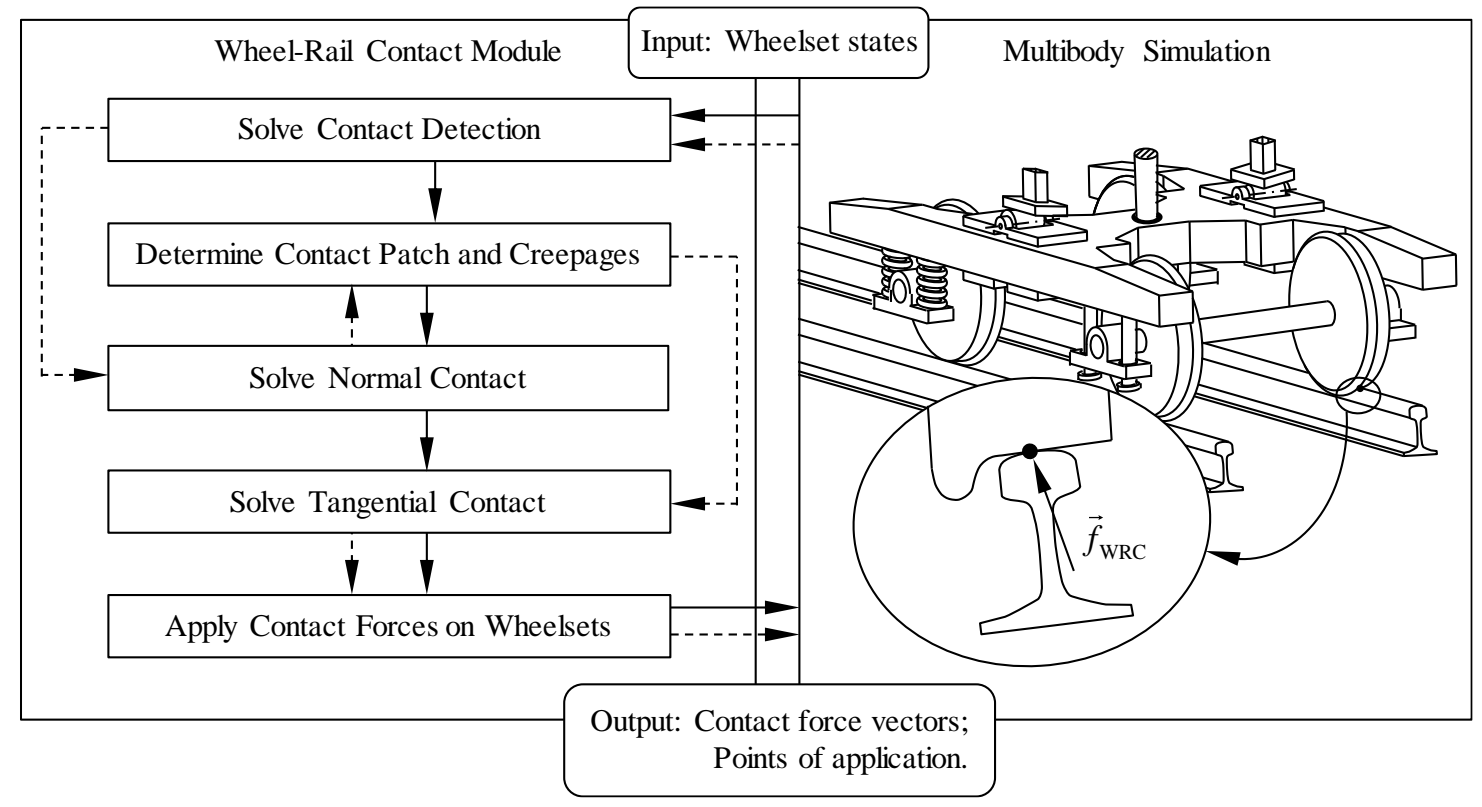

Fig. 1: Wheel-rail contact module of a multibody code where the interrupted and solid arrow paths refer to the Hertzian and non-Hertzian methods, respectively. 
In this work the multibody formulation is based on a Cartesian formulation where each body has six degrees-of-freedom described by the three translation coordinates $(x / y / z)$ and by four orientation coordinates represented by Euler parameters [26]. The governing equations of a railway vehicle system are written as [26]:

$$
\left[\begin{array}{cc}
\mathbf{M} & \boldsymbol{\Phi}_{\mathbf{q}}^{T} \\
\boldsymbol{\Phi}_{\mathbf{q}} & \mathbf{0}
\end{array}\right]\left[\begin{array}{l}
\ddot{\mathbf{q}} \\
\lambda
\end{array}\right]=\left[\begin{array}{l}
\mathbf{g} \\
\gamma
\end{array}\right]
$$

where $\mathbf{M}$ is the mass matrix, $\ddot{\mathbf{q}}$ is the vector of the system generalized accelerations, $\mathbf{g}$ is the external generalized forces vector, $\boldsymbol{\Phi}_{\mathbf{q}}$ is the Jacobian matrix associated with the kinematic constraints, $\lambda$ is the vector of Lagrange multipliers, which are related to the joint reaction forces and $\gamma$ is the right-hand side of the acceleration constraint equations. The forces developed at the contacting surfaces, represented in Fig. 1 by the vector $\mathbf{f}_{\mathrm{WRC}}$, are included in the term $\mathbf{g}$ as external forces.

It should be noted that, depending on the methods used, the interaction between system components can be set as kinematic constraints, therefore involving Jacobian matrix and acceleration equations right hand side, or contact forces may develop. For instance, the wheel-rail contact can be done modelled as a unilateral constraint as in or as a contact point as in this work. Also, the motor wheelset velocity may be controlled via a kinematic constraint or with applied moments. In this work, due to the short distances of circulations, large inertias involved and very low dissipation in the wheel-rail contact, no provisions are made to maintain the vehicle velocity constant, although it is basically unchanged in all studies shown here. Also, only the wheel-rail elastic contact is considering its description with unilateral constraints not addressed.

\section{Wheel and rail surface parameterization}

Since the forces developed in the contacting surfaces interface depend on the wheel-rail interference, the parameterization of the wheel and rail surfaces is required, that is, the position, tangent and normal vectors, and surface curvatures at any point of the surface must be defined as function of appropriate parameters. It should be noted that, in the formulation presented throughout this work, the superscripts ' $L$ ' and ' $R$ ' refer to the left and right side, respectively, while the superscript 'side' is used as a replacement for ' $L$ ' or ' $R$ ' when a generic left and/or right side is considered.

\begin{tabular}{|c|c|c|c|c|c|c|c|c|c|c|c|c|}
\hline$s_{\mathrm{r}, 1}^{\text {side }}$ & $r_{x, 1}^{\text {side }}$ & $r_{y, 1}^{\text {side }}$ & $r_{z, 1}^{\text {side }}$ & $t_{x, 1}^{\text {side }}$ & $t_{y, 1}^{\text {side }}$ & $t_{z, 1}^{\text {side }}$ & $n_{x, 1}^{\text {side }}$ & $n_{y, 1}^{\text {side }}$ & $n_{z, 1}^{\text {side }}$ & $b_{x, 1}^{\text {side }}$ & $b_{y, 1}^{\text {side }}$ & $b_{z, 1}^{\text {side }}$ \\
\hline$\vdots$ & $\vdots$ & $\vdots$ & $\vdots$ & $\vdots$ & $\vdots$ & $\vdots$ & $\vdots$ & $\vdots$ & $\vdots$ & $\vdots$ & $\vdots$ & $\vdots$ \\
\hline$s_{\mathrm{r}, j}^{\text {side }}$ & $r_{x, j}^{\text {side }}$ & $r_{y, j}^{\text {side }}$ & $r_{z, j}^{\text {side }}$ & $t_{x, j}^{\text {side }}$ & $t_{y, j}^{\text {side }}$ & $t_{z, j}^{\text {side }}$ & $n_{x, j}^{\text {side }}$ & $n_{y, j}^{\text {side }}$ & $n_{z, j}^{\text {side }}$ & $b_{x, j}^{\text {side }}$ & $b_{y, j}^{\text {side }}$ & $b_{z, j}^{\text {side }}$ \\
\hline$\vdots$ & $\vdots$ & $\vdots$ & $\vdots$ & $\vdots$ & $\vdots$ & $\vdots$ & $\vdots$ & $\vdots$ & $\vdots$ & $\vdots$ & $\vdots$ & $\vdots$ \\
\hline$s_{\mathrm{r}, \text { end }}^{\text {side }}$ & $r_{x, \text { end }}^{\text {side }}$ & $r_{y, \text { end }}^{\text {side }}$ & $r_{z, \text { end }}^{\text {side }}$ & $t_{x, \text { end }}^{\text {side }}$ & $t_{y, \text { end }}^{\text {side }}$ & $t_{z, \text { end }}^{\text {side }}$ & $n_{x, \text { end }}^{\text {side }}$ & $n_{y, \text { end }}^{\text {side }}$ & $n_{z, \text { end }}^{\text {side }}$ & $b_{x, \text { end }}^{\text {side }}$ & $b_{y, \text { end }}^{\text {side }}$ & $b_{z, \text { end }}^{\text {side }}$ \\
\hline
\end{tabular}

Tab. 1: Rail database that defines its position and orientation as a function of its arclength parameter [39, 40]

The wheel surface is obtained by the revolution sweep of the wheel cross-section, represented in Fig. 2(a), around its axis. In turn, the rail surface is described by the translational sweep of the rail cross-section shown in Fig. 2(b) along the rail path, which leads to a database that reflects the discretization of the rail and comprises a set of nodal points with the structure listed in Tab. 1. Each nodal point includes the position and orientation of the rail as a function of $s_{\mathrm{r}}^{\text {side }}$ which is a coordinate that defines the rail arclength shown in Fig. 3. The position of the rail profile origin is given by $\mathbf{r}_{\mathrm{r}}^{\text {side }}=\left[r_{x}^{\text {side }}, r_{y}^{\text {side }}, r_{z}^{\text {side }}\right]$, the unitary vector normal to the rail cross-section is defined by $\mathbf{t}_{\mathrm{r}}^{\text {side }}=\left[t_{x}^{\text {side }}, t_{y}^{\text {side }}, t_{z}^{\text {side }}\right]$, while $\mathbf{n}_{\mathrm{r}}^{\text {side }}=\left[n_{x}^{\text {side }}, n_{y}^{\text {side }}, n_{z}^{\text {side }}\right]$ is the unitary vector that corresponds to the transversal coordinate $u_{\mathrm{r}}^{\text {side }}$ and the unitary vector $\mathbf{b}_{\mathrm{r}}^{\text {side }}=\left[b_{x}^{\text {side }}, b_{y}^{\text {side }}, b_{z}^{\text {side }}\right]$ defines the coordinate $f_{\mathrm{r}}^{\text {side }}$, as shown in Fig. 2(b). Note that, the subscripts ' 1 ' and 'end' refer to the initial and terminal nodal points of the data bases, respectively, while ' $j$ ' refers to a generic nodal point of the rail database. This database is obtained with the pre- 
processor tool that uses the nominal track design geometry, namely, the curvature and cant angle, and the track irregularities to generate the current track geometry used in the railway dynamic analyses [39, 40]. Thus, the linear interpolation at $s_{\mathrm{r}}^{\text {side }}$ provides the position and orientation of the rail profile for the rail section located at the given arc length.

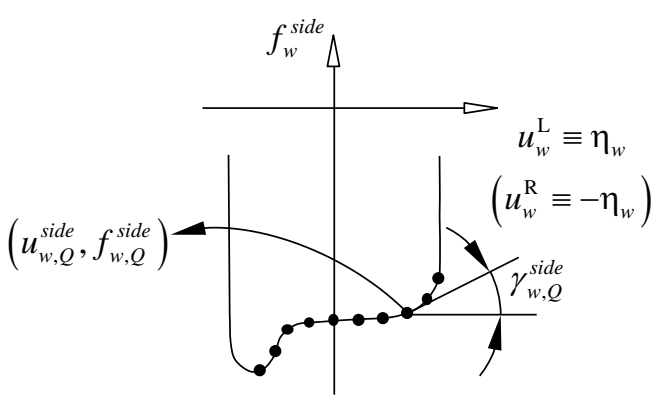

(a)

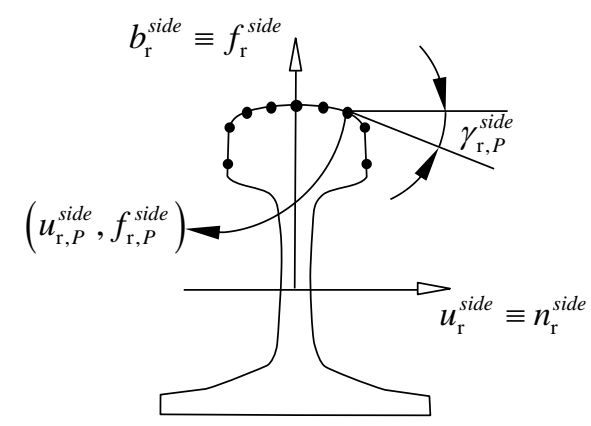

(b)

Fig. 2: (a) Wheel and (b) rail profiles defined by a set of nodal points

Once the wheel and rail cross-sections are specified by a set of nodal points, as illustrated in Fig. 2, the interpolation of this information provides a continuous description of the wheel and rail surfaces. Since the position, tangent and normal vectors, and the curvature at any point of the surfaces are required, the profiles are interpolated by cubic splines [1].

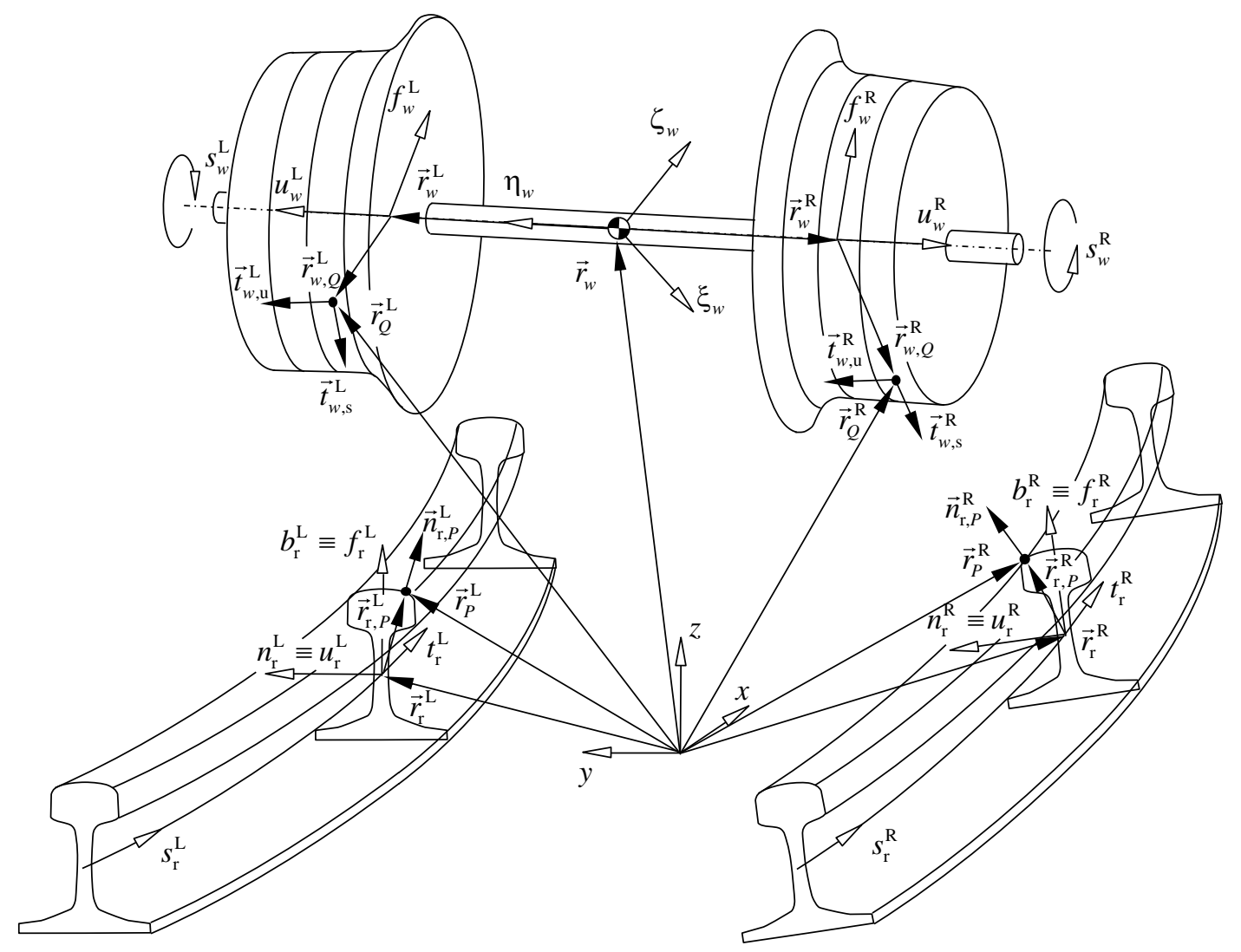

Fig. 3: Parameterization of the wheel and rail surfaces

The position of point $Q$ in the left or in the right wheel surface of wheelset $w$, that is, the vectors $\mathbf{r}_{Q}^{\mathrm{L}}$ and $\mathbf{r}_{Q}^{\mathrm{R}}$ shown in Fig. 3, can be written as: 


$$
\mathbf{r}_{Q}^{\text {side }}=\mathbf{r}_{w}+\mathbf{r}_{w}^{\text {side }}+\mathbf{r}_{w, Q}^{\text {side }}
$$

where $\mathbf{r}_{w}$ is the position vector of the wheelset $w, \mathbf{r}_{w}^{\text {side }}$ defines the relative position between the wheelset centre of mass, where the body fixed coordinate system is located, and the wheel profile origin, and $\mathbf{r}_{w, Q}^{\text {side }}$ defines the relative position between the wheel origin profile and the point $Q$, as shown in Fig. 3. Vector $\mathbf{r}_{w}^{\text {side }}$ is written as:

$$
\mathbf{r}_{w}^{\mathrm{L}}=\mathbf{A}_{w}\left[\begin{array}{lll}
0 & H / 2 & 0
\end{array}\right]^{\mathrm{T}} \quad, \quad \mathbf{r}_{w}^{\mathrm{R}}=\mathbf{A}_{w}\left[\begin{array}{lll}
0 & -H / 2 & 0
\end{array}\right]^{\mathrm{T}}
$$

where $\mathbf{A}_{w}$ is the transformation matrix of the wheelset $w$ that also defines the local reference frame attached to the wheelset $\left(\xi_{w} / \eta_{w} / \zeta_{w}\right)$, as depicted in Fig. 3, and $H$ is the distance between the left and right wheel profiles. The vector $\mathbf{r}_{w, Q}^{\text {side }}$ is defined as:

$$
\mathbf{r}_{w, Q}^{\text {side }}=\mathbf{A}_{w} \mathbf{A}_{w}^{\text {side }}\left[\begin{array}{lll}
0 & u_{w, Q}^{\text {side }} & f_{w, Q}^{\text {side }}
\end{array}\right]^{\mathrm{T}}
$$

in which $\left(u_{w, Q}^{\text {side }}, f_{w, Q}^{\text {side }}\right)$ are the coordinates of point $Q$ the two-dimensional reference frame $\left(u_{w}^{\text {side }} / f_{w}^{\text {side }}\right)$, as shown in Fig. 2(a). The rotation matrix $\mathbf{A}_{w}^{\text {side }}$ is defined as

$$
\mathbf{A}_{w}^{\mathrm{L}}=\left[\begin{array}{ccc}
\cos \left(s_{w, Q}^{\mathrm{L}}\right) & 0 & \sin \left(s_{w, Q}^{\mathrm{L}}\right) \\
0 & 1 & 0 \\
-\sin \left(s_{w, Q}^{\mathrm{L}}\right) & 0 & \cos \left(s_{w, Q}^{\mathrm{L}}\right)
\end{array}\right] \text { or } \quad \mathbf{A}_{w}^{\mathrm{R}}=\left[\begin{array}{ccc}
-\cos \left(s_{w, Q}^{\mathrm{R}}\right) & 0 & -\sin \left(s_{w, Q}^{\mathrm{R}}\right) \\
0 & -1 & 0 \\
-\sin \left(s_{w, Q}^{\mathrm{R}}\right) & 0 & \cos \left(s_{w, Q}^{\mathrm{R}}\right)
\end{array}\right]
$$

where $s_{w, Q}^{\mathrm{L}}$ and $s_{w, Q}^{\mathrm{R}}$ are the angular coordinates of point $Q$ in each wheel shown in Fig. 3. Thus, the two parameters $s_{w, Q}^{\text {side }}$ and $u_{w, Q}^{\text {side }}$ define any point of the wheel surface. For the wheel, two vectors tangent to the wheel surface must be defined [1,28]. The tangent vectors $\mathbf{t}_{w, s}^{\text {side }}$ and $\mathbf{t}_{w, u}^{\text {side }}$, depicted in Fig. 3, are used for the purpose. The tangent vectors parallel to the rolling motion of the left and right wheels are defined as:

$$
\mathbf{t}_{w, s}^{\mathrm{L}}=\mathbf{A}_{w} \mathbf{A}_{w}^{\mathrm{L}}\left[\begin{array}{lll}
1 & 0 & 0
\end{array}\right]^{\mathrm{T}} \quad, \quad \mathbf{t}_{w, s}^{\mathrm{R}}=\mathbf{A}_{w} \mathbf{A}_{w}^{\mathrm{R}}\left[\begin{array}{lll}
-1 & 0 & 0
\end{array}\right]^{\mathrm{T}}
$$

while the transversal tangent vectors are defined as:

$$
\mathbf{t}_{w, u}^{\text {side }}=\mathbf{A}_{w} \mathbf{A}_{w}^{\text {side }}\left[\begin{array}{lll}
0 & \cos \left(\gamma_{w, Q}^{\text {side }}\right) & \sin \left(\gamma_{w, Q}^{\text {side }}\right)
\end{array}\right]^{\mathrm{T}}
$$

where $\gamma_{w, Q}^{\text {side }}$ is the angle shown in Fig. 2(a) that can be determined by:

$$
\gamma_{w, Q}^{\text {side }}=\tan ^{-1}\left(\frac{d f_{w}^{\text {side }}\left(u_{w, Q}^{\text {side }}\right)}{d u_{w}^{\text {side }}}\right)
$$

The curvature of the wheel in the longitudinal direction is defined by:

$$
\kappa_{w, s}^{\text {side }}=\frac{1}{f_{w}^{\text {side }}\left(u_{w, Q}^{\text {side }}\right) \sqrt{1+\left(\frac{d f_{w}^{\text {side }}\left(u_{w, Q}^{\text {side }}\right)}{d u_{w}^{\text {side }}}\right)^{2}}}
$$

while in the transversal direction is expressed by: 


$$
\kappa_{w, u}^{\text {side }}=\left|\frac{\mathrm{d}^{2} f_{w, u}^{\text {side }}\left(u_{w, Q}^{\text {side }}\right)}{\mathrm{d}\left(u_{w}^{\text {side }}\right)^{2}} /\left[1+\left(\frac{\mathrm{d} f_{w}^{\text {side }}\left(u_{w, Q}^{\text {side }}\right)}{\mathrm{d} u_{w}^{\text {side }}}\right)^{2}\right]^{3 / 2}\right|
$$

The position of point $P$ in a rail surface is written as:

$$
\mathbf{r}_{P}^{\text {side }}=\mathbf{r}_{\mathrm{r}}^{\text {side }}+\mathbf{r}_{\mathrm{r}, P}^{\text {side }}
$$

where $\mathbf{r}_{\mathrm{r}}^{\text {side }}$ defines the position vector of the rail profile for a given $s_{\mathrm{r}}^{\text {side }}$, which is interpolated from the rail database, and $\mathbf{r}_{\mathrm{r}, P}^{\text {side }}$ is the position vector between the rail profile origin and the point $P$ of the rail, as shown in Fig. 3 , is defined as

$$
\mathbf{r}_{\mathrm{r}, P}^{\text {side }}=\mathbf{A}_{\mathrm{r}}^{\text {side }}\left[\begin{array}{lll}
0 & u_{\mathrm{r}, P}^{\text {side }} & f_{\mathrm{r}, P}^{\text {side }}
\end{array}\right]^{\mathrm{T}}
$$

where $\left(u_{\mathrm{r}, P}^{\text {side }}, f_{\mathrm{r}, P}^{\text {side }}\right)$ is the position of point $P$ measured in the profile reference frame $\left(u_{\mathrm{r}}^{\text {side }} / f_{\mathrm{r}}^{\text {side }}\right)$ as indicated in Fig. 2(b), and the transformation matrix $\mathbf{A}_{\mathrm{r}}^{\text {side }}=\left[\mathbf{t}_{\mathrm{r}}^{\text {side }}, \mathbf{n}_{\mathrm{r}}^{\text {side }}, \mathbf{b}_{\mathrm{r}}^{\text {side }}\right]$ associated to the local reference frame of the profile, as depicted in Fig. 3. The unity vectors of the tangent, normal and binormal of the rail at $s_{\mathrm{r}}^{\text {side }}$ are obtained from the interpolation of the rail database.

For the rail, the normal vector to its surface is required $[1,28]$, being the normal vector at point $P$ written as:

$$
\mathbf{n}_{\mathrm{r}, P}^{\text {side }}=\mathbf{A}_{\mathrm{r}}^{\text {side }}\left[\begin{array}{lll}
0 & -\sin \left(\gamma_{\mathrm{r}, P}^{\text {side }}\right) & \cos \left(\gamma_{\mathrm{r}, P}^{\text {side }}\right)
\end{array}\right]^{\mathrm{T}}
$$

where $\gamma_{\mathrm{r}, P}^{\text {side }}$ is the angle shown in Fig. 2(b) that can be determined by:

$$
\gamma_{\mathrm{r}, P}^{\text {side }}=\tan ^{-1}\left(\frac{\mathrm{d} f_{\mathrm{r}}^{\text {side }}\left(u_{\mathrm{r}, P}^{\text {side }}\right)}{\mathrm{d} u_{\mathrm{r}}^{\text {side }}}\right)
$$

The curvature of the rail in the longitudinal direction is defined by:

$$
\kappa_{\mathrm{r}, s}^{\text {side }}=0
$$

while in the transversal direction is obtained as:

$$
\kappa_{\mathrm{r}, u}^{\text {side }}=\left|\frac{\mathrm{d}^{2} f_{r}^{\text {side }}\left(u_{\mathrm{r}, P}^{\text {side }}\right)}{\mathrm{d}\left(u_{\mathrm{r}}^{\text {side }}\right)^{2}} /\left[1+\left(\frac{\mathrm{d} f_{\mathrm{r}}^{\text {side }}\left(u_{\mathrm{r}, P}^{\text {side }}\right)}{\mathrm{d} u_{\mathrm{r}}^{\text {side }}}\right)^{2}\right]^{3 / 2}\right|
$$

It must be noted that the assumption expressed by Eq. (15) is acceptable since in real tracks slope variations are very low.

\section{Geometry and kinematics of wheel-rail contact}

\subsection{Contact detection}

For the wheel-rail elastic contact models considered in this work, forces are transmitted between surfaces if virtual penetration between wheel and rail occurs. Note that the virtual penetration is understood as a local deformation of the surfaces. In the contact detection problem, it is necessary to use the tangent vectors $\mathbf{t}_{w, s}^{\text {side }}$ and $\mathbf{t}_{w, u}^{\text {side }}$, the normal vector $\mathbf{n}_{\mathrm{r}}^{\text {side }}$, and the distance vector $\mathbf{d}$, defined as: 


$$
\mathbf{d}^{\text {side }}=\mathbf{r}_{P}^{\text {side }}-\mathbf{r}_{Q}^{\text {side }}
$$

where points $Q$ and $P$ are defined by the parameters $\left(s_{w, Q}^{\text {side }}, u_{w, Q}^{\text {side }}\right)$ and $\left(s_{\mathrm{r}, P}^{\text {side }}, u_{\mathrm{r}, P}^{\text {side }}\right)$, respectively, as shown in Fig. 4 (a). In non-conformal scenarios, that is, when the contacting surfaces are convex, solving the contact detection problem consist of solving the system of four non-linear equations written as $[1,28]$ :

$$
\mathbf{F}_{\mathrm{nl}}\left(s_{w, Q}^{\text {side }}, u_{w, Q}^{\text {side }}, s_{\mathrm{r}, P}^{\text {side }}, u_{\mathrm{r}, P}^{\text {side }}\right)=\mathbf{0} \Leftrightarrow\left\{\begin{array}{l}
\left(\mathbf{n}_{\mathrm{r}}^{\text {side }}\right)^{\mathrm{T}} \mathbf{t}_{w, s}=0 \\
\left(\mathbf{n}_{\mathrm{r}}^{\text {side }}\right)^{\mathrm{T}} \mathbf{t}_{w, u}=0 \\
\left(\mathbf{d}_{\mathrm{r}}^{\text {side }}\right)^{\mathrm{T}} \mathbf{t}_{w, s}=0 \\
\left(\mathbf{d}_{\mathrm{r}}^{\text {side }}\right)^{\mathrm{T}} \mathbf{t}_{w, u}=0
\end{array}\right.
$$

The solution of this problem defines two potential points of contact, one in the wheel and another in the rail, for which vectors $\mathbf{n}_{\mathrm{r}}^{\text {side }}$ and $\mathbf{d}^{\text {side }}$ are collinear and perpendicular to the vectors $\mathbf{t}_{w, s}^{\text {side }}$ and $\mathbf{t}_{w, u}^{\text {side }}$, respectively. To verify that the contact between the wheel and rail exists, it is assessed the direction of vectors $\mathbf{n}_{\mathrm{r}}^{\text {side }}$ and $\mathbf{d}^{\text {side }}$, as shown in Fig. 4(b). If the $\mathbf{n}_{\mathrm{r}}^{\text {side }} \mathbf{d}^{\text {side }}>0$, then the surfaces are in contact, otherwise, no contact exists, being $\mathbf{d}^{\text {side }}$ the vector of the closest proximity between the surfaces.

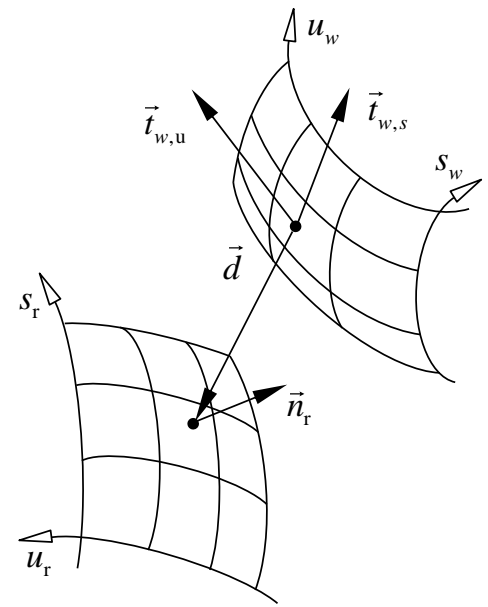

(a)

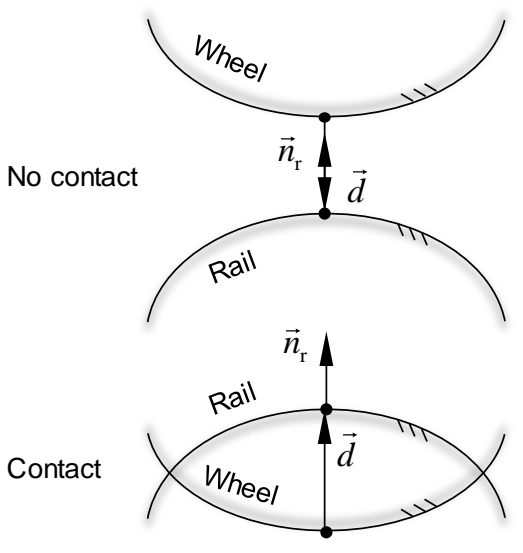

(b)

Fig. 4: (a) Vectors used for the contact detection between two surfaces and (b) the 'Contact' and 'No contact' configurations

The contact between the wheel tread and rail is searched independently of the contact between wheel flange and rail, as in both cases the contact is, generally, non-conformal. However, the interaction between the wheel and rail at the tread-flange transition cannot be identified by this search method since the non-conformality assumption is not valid in this region, that is, there is no guarantee that a solution for the problem defined by expression (18) exists. Moreover, the contact existing in this concave region would lead to a contact patch observed in a curved plane, for which there are no published contact models implemented in multibody codes that represent accurately the normal and tangential forces. Thus, two independent convex profiles are considered to describe the complete wheel profile, the tread and the flange profiles, and only two points of contact for a wheel-rail pair are possible at any particular instant, being one located in the tread and other in the flange.

\subsection{Contact patch}

When Hertzian contact is considered, the contact patch is assumed to be an ellipse that can be defined by the semi-axis [1]: 


$$
a=m \sqrt[3]{\frac{3 \pi}{4} \frac{h_{w}+h_{\mathrm{r}}}{A+B} N} \quad, \quad b=n \sqrt[3]{\frac{3 \pi}{4} \frac{h_{w}+h_{\mathrm{r}}}{A+B} N}
$$

where $m$ and $n$ are tabulated values [1], $h_{w}$ and $h_{\mathrm{r}}$ represent material parameters of the wheel and rail, respectively, $N$ denotes the normal contact force, and $A$ and $B$ are the curvatures written as:

$$
A=\frac{1}{2}\left(\kappa_{\mathrm{r}, u}^{\text {side }}+\kappa_{w, u}^{\text {side }}\right) \quad, \quad B=\frac{1}{2}\left(\kappa_{\mathrm{r}, s}^{\text {side }}+\kappa_{w, s}^{\text {side }}\right)
$$

in which curvatures $\kappa_{w, s}^{\text {side }}, \kappa_{w, u}^{\text {side }}, \kappa_{\mathrm{r}, s}^{\text {side }}$, and $\kappa_{\mathrm{r}, u}^{\text {side }}$ are determined by equations (9), (10), (15) and (16), respectively.

In the non-Hertzian contact, the shape of contact patch does not depend only on the properties of the main point of contact, being necessary to evaluate the undeformed distance function in a 'potential contact' region enclosing the geometric contact point in order to calculate the contact patch. This task requires the definition of the wheel and rail profiles with respect to the contact patch reference frame defined here by $\left(x_{\mathrm{cp}}^{\text {side }} / y_{\mathrm{cp}}^{\text {side }} / g_{\mathrm{cp}}^{\text {side }}\right.$ ) whose origin is the point of contact in the wheel, as shown in Fig. 5, and for which $x_{\mathrm{cp}}^{\text {side }} \equiv \mathbf{t}_{w, s}^{\text {side }}, y_{\mathrm{cp}}^{\text {side }} \equiv \mathbf{t}_{w, u}^{\text {side }}$ and $g_{\mathrm{cp}}^{\text {side }} \equiv \mathbf{n}_{\mathrm{r}}^{\text {side }}$. Note that only a portion of the wheel and rail profiles must be considered, namely, the region where virtual penetration occurs, being its domain shown in Fig. 5. In Fig. 5, the dots represent points in the contact region, while the crosses represent points where no interference occurs, being out of the domain of interest. The domain of axis $y_{\mathrm{cp}}^{\text {side }}$ is discretised by points equally spaced by $\Delta s$, in which $y_{\mathrm{cp}, i}^{\text {side }}=0$ is included in the domain. Moreover, since the wheel and rail profiles are projected onto the plane $\left(y_{\mathrm{cp}}^{\text {side }} / g_{\mathrm{cp}}^{\text {side }}\right)$, the coordinate $x_{\mathrm{cp}}^{\text {side }}$ is null for any point of the undeformed distance function.
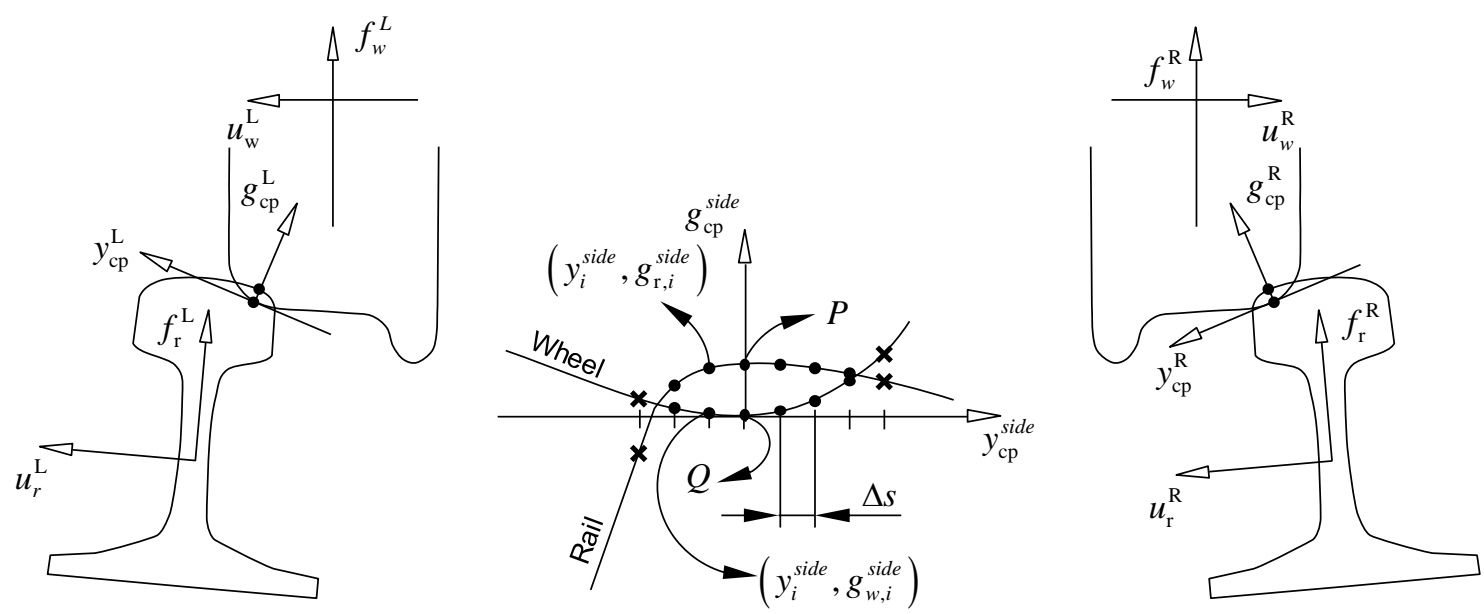

Fig. 5: Definition of the wheel and rail profile in the contact patch reference frame

The points $Q$ and $P$, in the reference frame ( $\left.y_{\mathrm{cp}}^{\text {side }} / g_{\mathrm{cp}}^{\text {side }}\right)$, are defined as $Q \equiv(0,0)$ and $P \equiv\left(0, \delta^{\text {side }}\right)$, where $\delta^{\text {side }}$ is the maximum penetration defined as:

$$
\delta^{\text {side }}=\sqrt{\left(\mathbf{d}^{\text {side }}\right)^{\mathrm{T}} \mathbf{d}^{\text {side }}}
$$

In order to determine the coordinates from any other point of the wheel and rail, namely, at $y_{\mathrm{cp}}^{\text {side }}=y_{i}^{\text {side }} \neq 0$, a transformation from the profile reference frame to the contact patch reference frame is required. For the wheel, the position vector of a point of the surface can be defined according to two different alternatives:

$$
\begin{aligned}
& \mathbf{r}_{y_{i}}^{\text {side }}=\mathbf{r}_{w}+\mathbf{r}_{w}^{\text {side }}+\mathbf{r}_{w, y_{i}}^{\text {side }} \\
& \mathbf{r}_{y_{i}}^{\text {side }}\left(y_{i}^{\text {side }}\right)=\mathbf{r}_{w}+\mathbf{r}_{w}^{\text {side }}+\mathbf{r}_{w, Q}^{\text {side }}+\mathbf{A}_{\mathrm{cp}}^{\text {side }}\left[\begin{array}{lll}
0 & y_{i}^{\text {side }} & g_{w, i}^{\text {side }}
\end{array}\right]^{\mathrm{T}}
\end{aligned}
$$


where the relation of these equations leads to:

$$
\left[\begin{array}{lll}
0 & y_{i}^{\text {side }} & g_{w, i}^{\text {side }}
\end{array}\right]^{\mathrm{T}}=\mathbf{B}^{\text {side }}\left[\begin{array}{ll}
0 & \left(u_{w, y}^{\text {side }}-u_{w, Q}^{\text {side }}\right) \\
\left(f_{w, y}^{\text {side }}-f_{w, Q}^{\text {side }}\right)
\end{array}\right]^{\mathrm{T}}
$$

with:

$$
\mathbf{B}^{\text {side }}=\left[\mathbf{A}_{\mathrm{cp}}^{\text {side }}\right]^{-1} \mathbf{A}_{w} \mathbf{A}_{w}^{\text {side }}
$$

being $\mathbf{A}_{\mathrm{cp}}^{\text {side }}=\left[\begin{array}{lll}\mathbf{t}_{w, s}^{\text {side }} & \mathbf{t}_{w, u}^{\text {side }} & \mathbf{n}_{\mathrm{r}}^{\text {side }}\end{array}\right]$. Note that the pair $\left(u_{w, y}^{\text {side }}, f_{w, y}^{\text {side }}\right)$ must be found by solving the non-linear equation written as:

$$
B_{(2,2)}^{\text {side }}\left(u_{w, y}^{\text {side }}-u_{w, Q}^{\text {side }}\right)+B_{(2,3)}^{\text {side }}\left(f_{w, y}^{\text {side }}-f_{w, Q}^{\text {side }}\right)-y_{w, i}^{\text {side }}=0
$$

where $u_{w, y}^{\text {side }}$ is the only unknown since $f_{w, y}^{\text {side }} \equiv f\left(u_{w, y}^{\text {side }}\right)$. Then, the ordinate of the wheel point at $y_{i}^{\text {side }}$ is defined as:

$$
g_{w, i}^{\text {side }}=B_{(3,2)}^{\text {side }}\left(u_{w, y}^{\text {side }}-u_{w, Q}^{\text {side }}\right)+B_{(3,3)}^{\text {side }}\left(f_{w, y}^{\text {side }}-f_{w, Q}^{\text {side }}\right)
$$

For the rail, the same procedure presented above is pursued. In this case, the two alternatives to define the position of a point of the rail at $y_{\mathrm{cp}}^{\text {side }}=y_{i}^{\text {side }}$ are:

$$
\begin{aligned}
& \mathbf{r}_{y_{i}}^{\text {side }}=\mathbf{r}_{\mathrm{r}}^{\text {side }}+\mathbf{r}_{\mathrm{r}, y_{i}}^{\text {side }} \\
& \mathbf{r}_{y_{i}}^{\text {side }}=\mathbf{r}_{\mathrm{r}}^{\text {side }}+\mathbf{r}_{\mathrm{r}, P}^{\text {side }}+\mathbf{A}_{\mathrm{cp}}^{\text {side }}\left[\begin{array}{lll}
0 & y_{i}^{\text {side }} & g_{r, i}^{\text {side }}-\delta
\end{array}\right]^{\mathrm{T}}
\end{aligned}
$$

where the relation of these equations leads to:

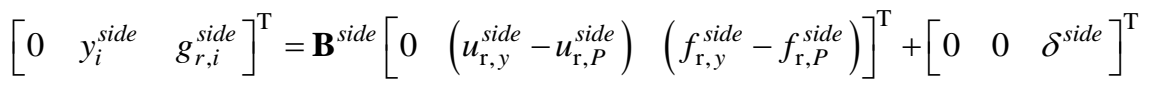

The parameter $u_{\mathrm{r}, y}^{\text {side }}$ is obtained by solving the non-linear equation written as:

$$
B_{(2,2)}^{\text {side }}\left(u_{\mathrm{r}, y}^{\text {side }}-u_{\mathrm{r}, P}^{\text {side }}\right)+B_{(2,3)}^{\text {side }}\left(f_{\mathrm{r}, y}^{\text {side }}-f_{\mathrm{r}, P}^{\text {side }}\right)-y_{i}^{\text {side }}=0
$$

and hence the ordinate of the rail point is defined as:

$$
g_{\mathrm{r}, i}^{\text {side }}=B_{(3,2)}^{\text {side }}\left(u_{\mathrm{r}, y}^{\text {side }}-u_{\mathrm{r}, P}^{\text {side }}\right)+B_{(3,3)}^{\text {side }}\left(f_{\mathrm{r}, y}^{\text {side }}-f_{\mathrm{r}, P}^{\text {side }}\right)+\delta^{\text {side }}
$$

Since both profiles are defined with respect to the contact patch reference frame, the undeformed distance function is obtained as [58]:

$$
g_{\text {und }}^{\text {side }}\left(y_{i}^{\text {side }}\right)=g_{w}^{\text {side }}\left(y_{i}^{\text {side }}\right)-g_{\mathrm{r}}^{\text {side }}\left(y_{i}^{\text {side }}\right)+\delta^{\text {side }}
$$

Fig. 6(a) shows an example for the undeformed distance function. Thus, the contact patch can be determined, being the positive edge of the contact patch defined as [59]:

$$
x_{\mathrm{L}}\left(y_{i}^{\text {side }}\right)=\sqrt{2 R_{Q}\left(\varepsilon \delta^{\text {side }}-g_{\text {und }}^{\text {side }}\left(y_{i}^{\text {side }}\right)\right)}
$$

where $\varepsilon$ is a parameter that takes into account the existing deformation to estimate the contacting area [59] and $R_{Q}$ denotes the radius at the contact patch in the rolling direction in point $Q$, written as: 


$$
R_{Q}=-f_{w, Q}^{\text {side }} \sqrt{1+\left(\frac{\mathrm{d} f_{w, Q}^{\text {side }}}{\mathrm{d} u_{w}^{\text {side }}}\right)^{2}}
$$

Note that the contact patch consists of a set of strips, being the contact patch symmetric with respect to the $y_{\mathrm{cp}}^{\text {side }}$ axis, as shown in Fig. 6(b), also called semi-Hertzian contact patch.

Special emphasis is put in the two points shown in Fig. 6 with a circle 'o', which represent the limits of the undeformed distance function. These points correspond to the value of the undeformed distance function as $g_{\mathrm{cp}}^{\text {side }}$ $=\varepsilon \delta$, as depicted in Fig. 6(a), and obtained via linear interpolation between the point outside the contact and the closest point in the contact region. Thus, the intersection of the line edge of the contact patch in the axis $y_{\mathrm{cp}}^{\text {side }}$ is ensured, as shown in Fig. 6(b). A strip, with a width smaller than $\Delta s$, is added at each extremity of the contact to account for the correct limits of the contact patch. When these two limiting strips are not considered, the continuity of the contact patch is not ensured during the dynamic simulation leading to numerical instabilities that ultimately lead to a degradation of the dynamic response.

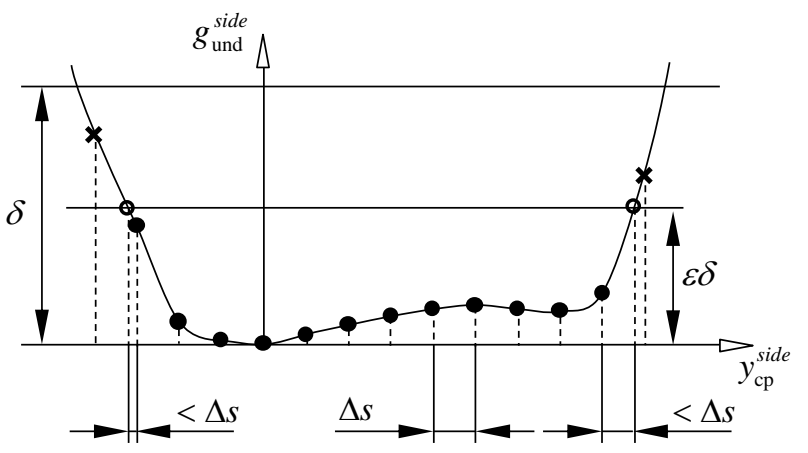

(a)

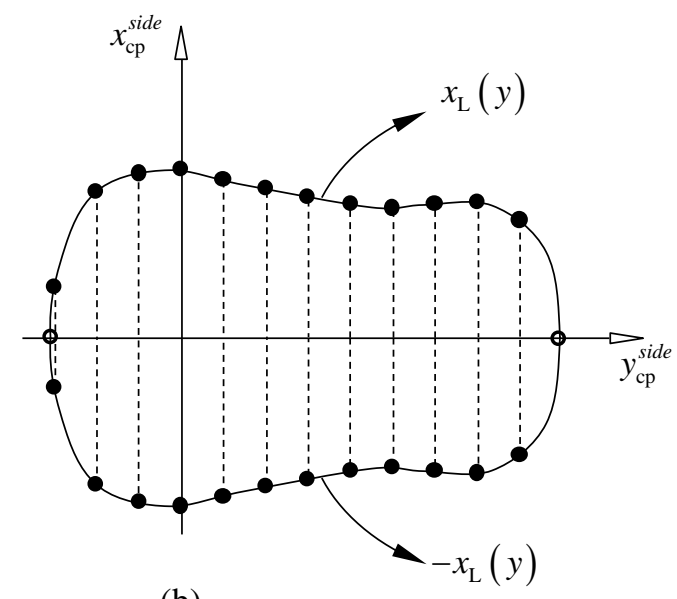

(b)

Fig. 6: (a) Undeformed distance function and (b) contact patch

It is worth notice that the undeformed distance function shown in Fig. 6(a) consists of a generalized case that represents the contact in the concave region of the wheel. Here, the non-conformal assumption is not valid since more than one solution exists for the contact detection problem expressed by equation (18), namely, the two minima and the maxima of the undeformed distance function satisfy the conditions to be a potential point of contact. In this work, the concave region of the wheel is neglected by modifying slightly its profile in the transition between the tread and flange, namely, the curvature in this concave region is forced to be null. Thus, a unique solution is ensured for the contact detection problem proposed in this work. The validity of this approach that permits up to two contacts, one in the tread and other in the flange, depends on the wheel-rail pair and on the relative motion of the wheelset in the track. To deal with the conformal contact that would determine an undeformed distance function as the one shown in Fig. 6(a), a different contact detection method would be required. This method must allow determining multiple contacts and contact patches in curved planes. Because accurate contact models for conformal contact in multibody applications is still a gap in the literature, the simplification of the wheel profile is considered in this work as it is made by other authors [1,34, 47]. The extension of the wheel-rail contact model proposed in this work in order to deal with conformal contact is the aim of future developments. 


\subsection{Creepages}

Once the contacting patch area is identified, a kinematic analysis in this region allows to find the longitudinal, lateral and spin creepages, defined as:

$$
\begin{gathered}
v_{x}=\frac{\mathbf{v}_{\mathrm{rel}}^{\mathrm{T}} \mathbf{t}_{w, s}}{V_{w}} \\
v_{y}=\frac{\mathbf{v}_{\mathrm{rel}}^{\mathrm{T}} \mathbf{t}_{w, u}}{V_{w}} \\
\varphi=\frac{\boldsymbol{\omega}_{w}^{\mathrm{T}} \mathbf{n}_{\mathrm{r}}}{V_{w}}
\end{gathered}
$$

where $V_{w}$ and $\boldsymbol{\omega}_{w}$ are the absolute longitudinal velocity and the angular velocity of the wheelset $w$, respectively, and $\mathbf{v}_{\text {rel }}$ is the relative speed at the contacting points defined as:

$$
\mathbf{v}_{\text {rel }}=\mathbf{v}_{Q}-\mathbf{v}_{P}
$$

where $\mathbf{v}_{P}$ is null since the track is considered rigid, and:

$$
\mathbf{v}_{Q}=\mathbf{v}_{w}+\boldsymbol{\omega}_{w}\left(\mathbf{r}_{w}^{\text {side }}+\mathbf{r}_{w, Q}^{\text {side }}\right)
$$

Note that the spin creepage is expected to be not null, in normal conditions, since the normal vector $\mathbf{n}_{\mathrm{r}}$ of the contacting region and the angular speed vector $\boldsymbol{\omega}_{w}$ are not necessarily perpendicular.

\section{Normal contact}

This section provides a brief description of the LN model [62, 63] for the Hertzian contact model [1], and a detailed description of the KP model [59] for the non-Hertzian contact method. A discussion on the application of these models is presented in section 7 , included in the study of a demonstration case.

\subsection{Lankarani-Nikravesh model}

According to the Hertz theory, the normal contact force between two isotropic and elastic spherical bodies made of metal follows the relation [58]:

$$
N^{\mathrm{H}}=K \delta^{1.5}
$$

where parameter $K$ is a generalized stiffness coefficient that depends on the geometry of the surfaces in contact and on their material properties. An extension of this theory has been proposed to include a damping force [79]:

$$
N^{\mathrm{KV}}=N^{\mathrm{H}}+D \dot{\delta}
$$

where $\dot{\delta}$ denotes the normal contact relative velocity. According to Hunt and Crossley [80], the term $D$ depends on the deformation and, based on this idea, Lankarani and Nikravesh defined the damping term as [62, 63]:

$$
D=\frac{3 K\left(1-e^{2}\right)}{4 \dot{\delta}^{(-)}} \delta^{n}
$$

where $e$ is the restitution coefficient that reflects the type of impact, in which for a fully elastic contact $e=1$ and for a fully plastic contact $e=0$. The parameter $\dot{\delta}^{(-)}$is the relative approach velocity, or normal contact velocity, between the bodies immediately before the impact. Thus, the normal contact force model is written as [62, 63]: 


$$
N^{\mathrm{LN}}=K \delta^{1.5}\left(1+\frac{3\left(1-e^{2}\right)}{4} \frac{\dot{\delta}}{\dot{\delta}^{(-)}}\right)
$$

This model has been adapted by Pombo et al. [1, 28] for railway applications, being proposed that the normal wheel-rail contact force is defined as:

$$
N^{\mathrm{LN}}=\max \left(N^{\mathrm{H}}\left(1+\frac{3\left(1-e^{2}\right)}{4} \frac{\dot{\delta}}{\dot{\delta}^{\max }}\right), 0\right)
$$

where $\dot{\delta}^{\text {max }}$ is defined as the maximum value $\dot{\delta}$ during the contact such that the ratio $\dot{\delta} / \dot{\delta}^{\max } \leq 1$. Note that the damping effect is not only used to represent the restitution effect, but also to mitigate high frequency behaviour due to the wheel-rail interaction. Thus, the damping in the normal contact helps the numerical integration by mitigating numerical instabilities when no other source of damping in the multibody model exists besides that naturally associated to the wheel-rail contact, such as in the case of a wheelset negotiating a rigid track.

\subsection{Kik-Piotrowski model}

For the non-Hertzian contact, the normal contact pressure proposed by Kik and Piotrowski is used [59]. In this model, a semi-elliptic normal pressure distribution is assumed in the rolling direction, as depicted in Fig. 7(a) and which can be expressed as [59]:

$$
p\left(x_{\mathrm{cp}}, y_{\mathrm{cp}}\right)=\frac{p_{0}}{x_{\mathrm{L}}(0)} \sqrt{x_{\mathrm{L}}^{2}\left(y_{\mathrm{cp}}\right)-x_{\mathrm{cp}}^{2}}
$$

where $p_{0}$ is the maximum normal pressure. Since during the multibody simulation $p_{0}$ is not known, the KikPiotrowski model estimates the maximum pressure as [59]:

$$
p_{0}=\frac{\pi E \delta x_{\mathrm{L}}(0)}{2\left(1-\sigma^{2}\right)}\left[\int_{y_{\mathrm{L}}-x_{\mathrm{L}}\left(y_{\mathrm{cp}}\right)}^{y_{\mathrm{R}}} \int_{\mathrm{L}_{\mathrm{Lp}}\left(y_{\mathrm{cp}}\right)}^{\sqrt{x_{\mathrm{L}}^{2}(y)-x_{\mathrm{cp}}^{2}}} \mathrm{~d} x_{\mathrm{cp}} \mathrm{d} y_{\mathrm{cp}}\right]^{-1}
$$

where $E$ and $\sigma$ are the Young's modulus and the Poisson's ratio of the wheel and rail materials, respectively. For the multibody simulation, the normal contact force is required. This normal contact force results from the integration of the pressure distribution over the contacting area, written as [59]:

$$
N^{\mathrm{KP}}=\frac{\pi E \delta}{2\left(1-\sigma^{2}\right)}\left[\int_{y_{\mathrm{L}}-x_{\mathrm{L}}\left(y_{\mathrm{cp}}\right)}^{y_{\mathrm{R}}} \int_{\mathrm{L}}^{x_{\mathrm{L}}\left(y_{\mathrm{cp}}\right)} \frac{\sqrt{x_{\mathrm{L}}^{2}\left(y_{\mathrm{cp}}\right)-x_{\mathrm{cp}}^{2}}}{\sqrt{x_{\mathrm{cp}}^{2}+y_{\mathrm{cp}}^{2}}} \mathrm{~d} x_{\mathrm{cp}} \mathrm{d} y_{\mathrm{cp}}\right]^{-1} \int_{y_{\mathrm{L}}}^{y_{\mathrm{R}}} \int_{x_{\mathrm{L}}\left(y_{\mathrm{cp}}\right)}^{x_{\mathrm{L}}\left(y_{\mathrm{cp}}\right)} \sqrt{x_{\mathrm{L}}^{2}\left(y_{\mathrm{cp}}\right)-x_{\mathrm{cp}}^{2}} \mathrm{~d} x_{\mathrm{cp}} \mathrm{d} y_{\mathrm{cp}}
$$

Note that the first integral contains a singularity at $\left(x_{\mathrm{cp},}, y_{\mathrm{cp}}\right)=(0,0)$, namely, at this point the first integrating function tends to infinity. By using a numerical integration method based on Cartesian coordinates, the result would strongly depend not only on the points where the function is evaluated, but also on the discretization of the integration area. To overcome this difficulty, a polar coordinate system is used to perform the integration, as shown in Fig. 7(b). In this conversion, the following relations are used: 


$$
\begin{aligned}
& r=\sqrt{x_{\mathrm{cp}}^{2}+y_{\mathrm{cp}}^{2}} \\
& x_{\mathrm{cp}}=r \sin (\theta) \\
& y_{\mathrm{cp}}=r \cos (\theta) \\
& \mathrm{d} x_{\mathrm{cp}} \mathrm{d} y_{\mathrm{cp}}=r \mathrm{~d} r \mathrm{~d} \theta
\end{aligned}
$$

being the normal contact force of the KP model obtained in polar coordinates as:

$$
N^{\mathrm{KP}}=\frac{\pi E \delta}{2\left(1-\sigma^{2}\right)} \frac{\int_{0}^{\pi} \int_{0}^{r_{\mathrm{L}}(\theta)} r \sqrt{x_{\mathrm{L}}^{2}(r \cos (\theta))-(r \sin (\theta))^{2}} \mathrm{~d} r \mathrm{~d} \theta}{\int_{0}^{r_{\mathrm{L}}(\theta)} \int_{0}^{2} \sqrt{x_{\mathrm{L}}^{2}(r \cos (\theta))-(r \sin (\theta))^{2}} \mathrm{~d} r \mathrm{~d} \theta}
$$

In the evaluation of the integrals, for the $\theta$ coordinate, only half of the contact area is considered due to the symmetry of the contact patch with respect axis $y_{\mathrm{cp}}$. Moreover, the limits for the $r$ coordinate depends on $\theta$, namely, only the area contained within the thick line show in Fig. 7(b) is considered. To speed up the calculations, the trapezoidal integral method is used, being $N^{\mathrm{KP}}$ obtained as:

$$
N^{\mathrm{KP}}=\frac{\pi E \delta}{2\left(1-\sigma^{2}\right)} \frac{\sum_{i=1}^{N_{\theta}} \sum_{j=1}^{N_{\mathrm{r}}\left(\theta_{i}\right)} r_{j} \sqrt{x_{\mathrm{L}}^{2}\left(r_{j} \cos \left(\theta_{i}\right)\right)-\left(r_{j} \sin \left(\theta_{i}\right)\right)^{2}} \Delta r \Delta \theta}{\sum_{i=1}^{N_{\theta}} \sum_{j=1}^{N_{\mathrm{r}}\left(\theta_{i}\right)} \sqrt{x_{\mathrm{L}}^{2}\left(r_{j} \cos \left(\theta_{i}\right)\right)-\left(r_{j} \sin \left(\theta_{i}\right)\right)^{2}} \Delta r \Delta \theta}
$$

where $\Delta \theta$ and $\Delta r$ are the step sizes for the coordinates $\theta$ and $r$, respectively. Note that $N_{\theta}=\pi / \Delta \theta$ which is the number of angular sectors used to discretize the contact patch, while $N_{\mathrm{r}}$ is the number of steps considered for a given $\theta_{i}$.

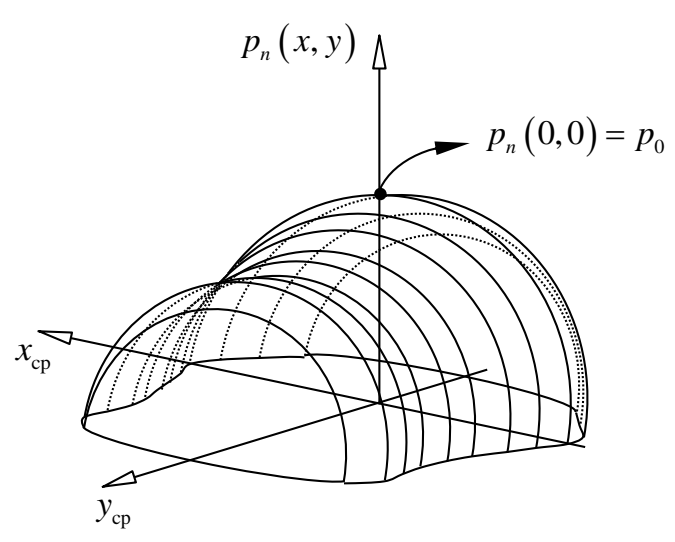

(a)

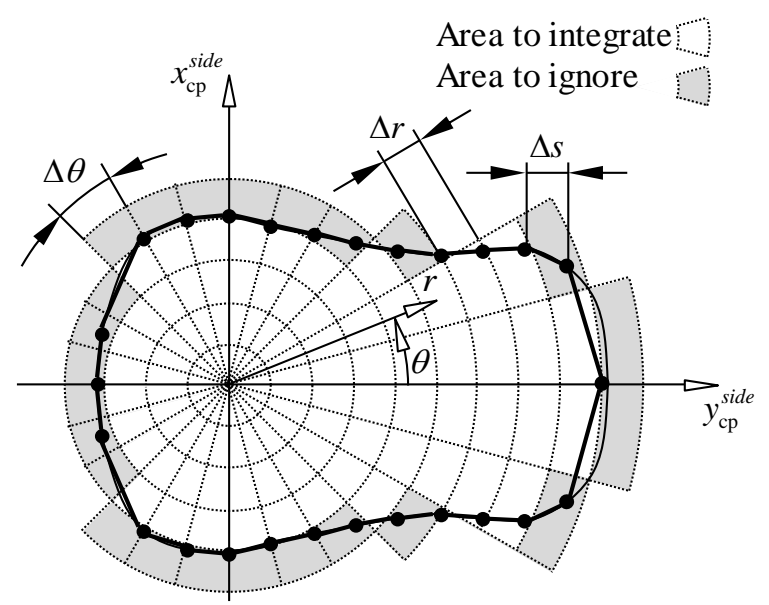

(b)

Fig. 7: For a rolling direction along $x_{\mathrm{cp}}$ : (a) Normal pressure distribution of the KP model and (b) integration area defined by a polar coordinate system

An alternative to the original KP model consists of adding a dissipative term to KP model, maintainning the equivalent feature in the LN model. This proposed alterantive model is written as: 


$$
N^{\mathrm{KP}, \mathrm{d}}=\max \left(N^{\mathrm{KP}}\left(1+\frac{3\left(1-e^{2}\right)}{4} \frac{\dot{\delta}}{\dot{\delta}^{\max }}\right), 0\right)
$$

Note that the introduction of the dissipative term not only reflects the mechanics of the normal contact but also contributes to the numerical stability of the time integration process of the dynamic equations of motion of the railway dynamics system.

\section{Tangential contact}

This section provides a brief description of the Polach model [69] for the Hertzian contact model [1], and a detailed description of the KBTNH model $[20,21]$ for the non-Hertzian contact method. A discussion of these models presented in section 7 in the framework of the demonstration case.

\subsection{Polach model}

For the Hertzian methodology, the Polach model is used to determine the longitudinal and lateral creepages, neglecting the spin creep moment [69]. These forces are defined as:

$$
F_{\mathrm{x}}^{\text {Polach }}=F \frac{v_{\mathrm{x}}}{v_{\mathrm{C}}}, \quad F_{\mathrm{y}}^{\text {Polach }}=F \frac{v_{\mathrm{y}}}{v_{\mathrm{C}}}+F_{\eta S} \frac{\varphi}{v_{\mathrm{C}}} \quad, \quad M_{\mathrm{z}}^{\text {Polach }}=0
$$

where $F$ is the tangential contact force caused by longitudinal and lateral creepages, $v_{\mathrm{C}}$ is the modified translational creepage, which accounts the effect of spin creepage, and $F_{\eta S}$ is the lateral tangential force caused by spin creepage. The reader is referred to reference [69] for more details on the calculation of $F, v_{\mathrm{C}}$ and $F_{\eta S}$.

\subsection{KBTNH model}

For the non-Hertzian approach to wheel-rail contact, the so-called Kalker Book of Tables for Non-Hertzian (KBTNH) contact, proposed by Piotrowski et al., is used here [20, 21]. This model approximates the nonHertzian contact patch by a single double-elliptical contact (SDEC), as shown in Fig. 8. To interpolate the KBTNH and hence to obtain the tangential contact forces, five regularized inputs must be determined. Three of the inputs are related to the normalised longitudinal, lateral and spin creepages being defined as:

$$
\xi=\frac{\rho v_{\mathrm{x}}}{\mu c} \quad, \quad \eta=\frac{\rho v_{\mathrm{y}}}{\mu c} \quad, \quad \chi=\frac{\rho \varphi}{\mu}
$$

where $\rho$ is a characteristic length of the elliptical contact patch, $\mu$ is the friction coefficient and $c=\sqrt{a b}[20,21]$. The normalised creepages $\xi$ and $\eta$ are alternatively defined by:

$$
v=\sqrt{\xi^{2}+\eta^{2}} \quad, \quad \alpha=\tan ^{-1}\left(\frac{\eta}{\xi}\right)
$$

where $v$ is the translational creep magnitude and $\alpha$ is directional angle with respect to the rolling direction, respectively. The pair $v$ and $\alpha$ is considered to define the domain of the KBTNH. Two input parameters related to the shape of the contact patch are defined as

$$
g=\frac{a}{b} \quad, \quad \psi=\frac{y_{0}}{b}
$$

where $a, b$ and $y_{0}$ are the dimensions of the SDEC region, shown in Fig. 8(b), obtained as: 


$$
a=\sqrt{\frac{A_{\mathrm{cp}}}{\pi} \frac{W_{3}}{\left(W_{1}+W_{2}\right)}} \quad, \quad b=\sqrt{\frac{A_{\mathrm{cp}}}{\pi} \frac{\left(W_{1}+W_{2}\right)}{W_{3}}} \quad, \quad y_{0}=b \frac{W_{1}-W_{2}}{W_{1}+W_{2}}
$$

where $A_{\mathrm{cp}}$ is the area of the contact patch, and $W_{1}, W_{2}$ and $W_{3}$ are the dimensions depicted in Fig. 8(a). The outputs of the KBTNH are the normalised creep forces $f_{x}$ and $f_{y}$ and the normalised creep moment $m_{z}$, obtained from linear interpolation of the pre-calculated lookup table. The creep forces are obtained as:

$$
F_{\mathrm{x}}^{\mathrm{KBTNH}}=\mu N f_{\mathrm{x}} \quad, \quad F_{\mathrm{y}}^{\mathrm{KBTNH}}=\mu N f_{\mathrm{y}} \quad, \quad M_{\mathrm{z}}^{\mathrm{KBTNH}}=\mu c N m_{\mathrm{z}}
$$

The discretization and the number of points considered for each input of the KBTNH are listed in Tab. 2. Note that, owing to the symmetry properties of the SDEC shape, $\alpha$ only covers the domain $[-\pi / 2 ; \pi / 2]$, while only positive values of $\chi$ are considered. To determine contact forces for the remaining cases, not comprised in the KBTNH domain, the symmetries listed in Tab. 3 are used. The right column of this table represents the domain described in Tab. 2. In each cell of this table, it is described not only the sign of the interpolated variables $\xi, \eta, \chi$ and $\psi$, but also by the outputs of the lookup table. For example, for a set of inputs that fits the conditions $\xi<0, \eta \geq 0, \chi<0$ and $\psi \geq 0$, which is defined by the cell in the top left, the outputs are obtained based on the ones listed in the cell in $3^{\text {rd }}$ row of the right column, that is, $f_{x}=-f_{x}^{3}, f_{y}=-f_{y}^{3}$ and $m_{z}=-m_{z}^{3}$. Therefore, the lookup table constituting the KBTNH has to be generated only for the sign combinations shown in the right column of Table 3, whilst the other cases can be obtained based on symmetry relations.

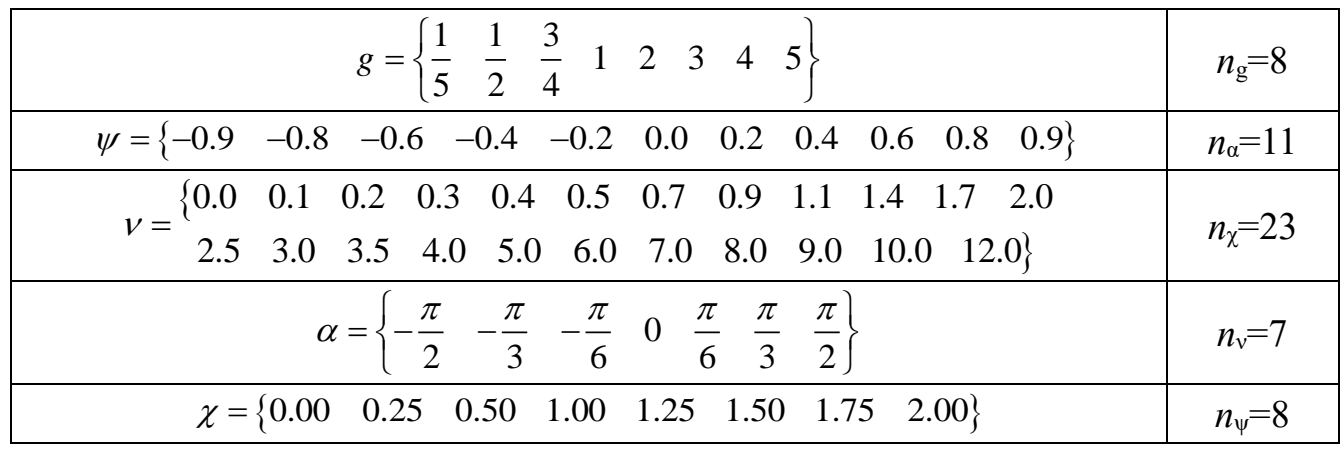

Tab. 2: Domain of the Kalker Book of Tables for Non-Hertzian (KBTNH) contact [20]

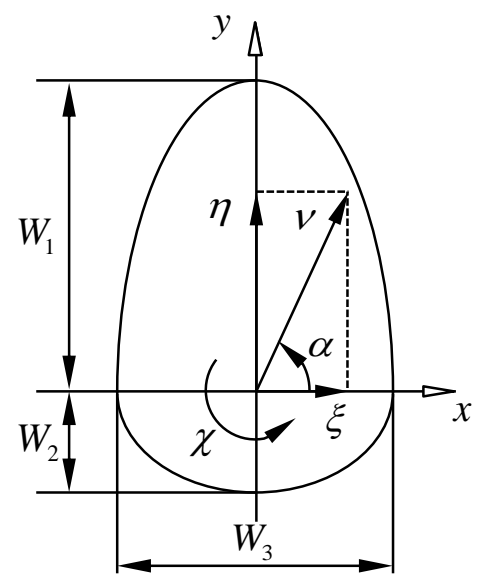

(a)

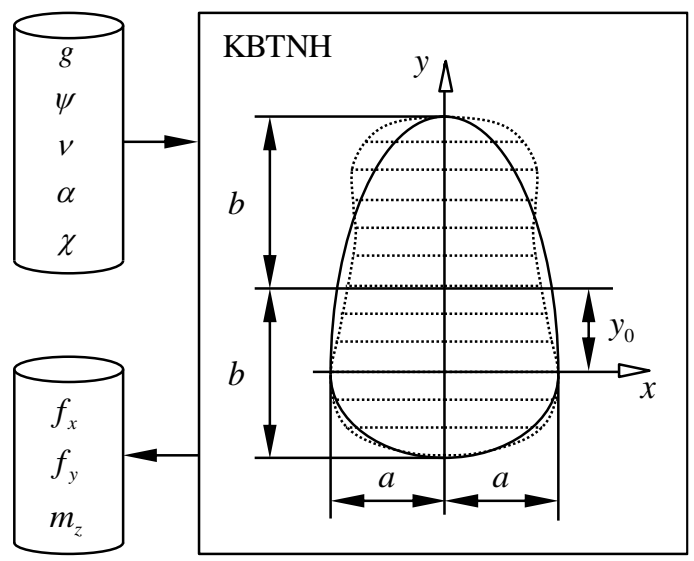

(b)

Fig. 8: (a) Simple double-elliptical contact patch and creepages, and (b) input and output of the KBTNH 


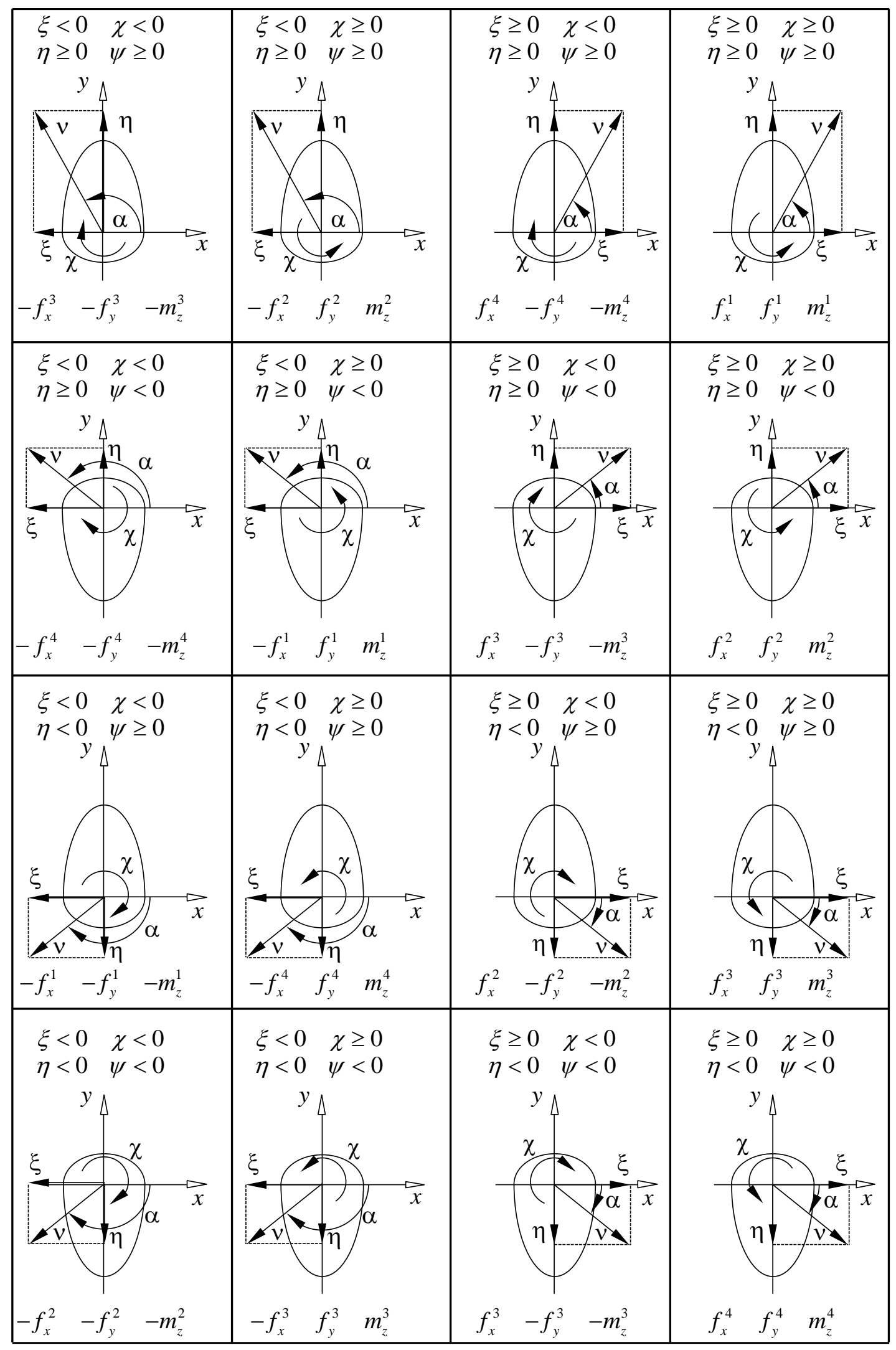

Tab. 3: Symmetries of the KBTNH [20, 21] 


\section{Demonstration cases}

With the purpose of analysing the wheel-rail contact models presented in this work, static contact and dynamic analyses have been performed in selected applications cases. The contact analysis, or static analysis, in which the wheel and rail are tested for different pseudo-penetrations and creepages, serves to validate the contact models by comparing with software CONTACT. The dynamic analysis consists of multibody simulations where the Hertzian and non-Hertzian contact models discussed in this work are used to represent the wheel-rail contact forces. The results obtained from the multibody simulations are used not only to assess the wheel-rail interaction, but also to analyse the computational efficiency of the procedures proposed. The ML95 vehicle, operated by the Lisbon Metro has been considered in all cases [1,28], whereof the wheel and rail profiles are shown in Fig. 9 and the modelling parameters of the application cases are listed in Tab. 4.

\begin{tabular}{|c|c|}
\hline Parameter & Value \\
\hline Mass of the vehicle and weight per wheel & $19560 \mathrm{~kg}$ and $23985 \mathrm{~N}$ \\
\hline Mass of the bogie system and weight per wheel & $4200 \mathrm{~kg}$ and $10301 \mathrm{~N}$ \\
\hline Mass of the wheelset and weight per wheel & $1109 \mathrm{~kg}$ and $5440 \mathrm{~N}$ \\
\hline Nominal wheel radius, $R$ & $0.430 \mathrm{~m}$ \\
\hline Distance between wheel profiles, $H$ & $1.500 \mathrm{~m}$ \\
\hline Distance between points of contact, $H^{*}$ & $1.525 \mathrm{~m}$ \\
\hline Young modulus, $E$ & $208 \mathrm{GPa}$ \\
\hline Shear modulus, $G$ & $80 \mathrm{GPa}$ \\
\hline Friction coefficient, $\mu$ & 0.3 \\
\hline Restitution coefficient, $e$ & 1 or 0.75 \\
\hline Poisson ratio, $\sigma$ & 0.3 \\
\hline Parameter for the undeformed distance function, $\varepsilon$ & $0.55[59]$ \\
\hline Rail cant & $1 / 20$ or $2.87^{\circ}$ \\
\hline Gauge & $1.435 \mathrm{~m}$ \\
\hline Longitudinal stiffness of PS & $12.420 \mathrm{MN} / \mathrm{m}$ \\
\hline Lateral stiffness of PS & $2.060 \mathrm{MN} / \mathrm{m}$ \\
\hline Vertical stiffness of PS & $1.280 \mathrm{MN} / \mathrm{m}$ \\
\hline Longitudinal damping of PS & $172.580 \mathrm{kNs} / \mathrm{m}$ \\
\hline Lateral damping of PS & $70.290 \mathrm{kNs} / \mathrm{m}$ \\
\hline Vertical damping of PS & $55.410 \mathrm{kNs} / \mathrm{m}$ \\
\hline Longitudinal stiffness of SS & $0.075 \mathrm{MN} / \mathrm{m}$ \\
\hline Lateral stiffness of SS & $0.750 \mathrm{MN} / \mathrm{m}$ \\
\hline Vertical stiffness of SS & $0.250 \mathrm{MN} / \mathrm{m}$ \\
\hline Longitudinal damping of SS & $26.038 \mathrm{kNs} / \mathrm{m}$ \\
\hline Lateral damping of SS & $26.038 \mathrm{kNs} / \mathrm{m}$ \\
\hline Vertical damping of SS & $68.538 \mathrm{kNs} / \mathrm{m}$ \\
\hline
\end{tabular}

Tab. 4: General characteristics of the ML95 vehicle $[1,28]$

Three multibody models are considered in this work to represent the wheelset, the bogie system and the whole vehicle. The bogie system comprises a bogie frame and two wheelsets that are interconnected by the primary suspension. The vehicle comprises a carbody and two bogie systems that are interconnected through the secondary suspension. Both suspensions are represented by linear spring-damper elements that are described in references $[1,28,81]$. The wheel profile is defined by the two set of nodal points shown in Fig. 9(a) which are obtained based on the S1002 profile. The tread and flange profiles are extended, crossing each other as shown in 
Fig. 9(a). This is done to ensure a solution for the contact detection problem during the multibody simulation, meaning that potential points of contact that lie in these segments do not represent points contacting the rail. Note that the deviation from the real profile is acceptable according to the results presented hereafter, meaning that no contact is expected at the flange-tread transition. In turn, the rail profile UIC50 is obtained without introducing any approximation. The analyses presented throughout this section are intended not only to demonstrate the wheel-rail contact models and discuss their accuracy, but also to identify proper parameters for the Hertzian and non-Hertzian contact models, namely, $e, \Delta s, \Delta r$ and $\Delta \theta$. The relation $\Delta s=\Delta r$, for the quantities defined in Fig. 7, is used throughout the study to decrease the number of parameters required to define the contact models.

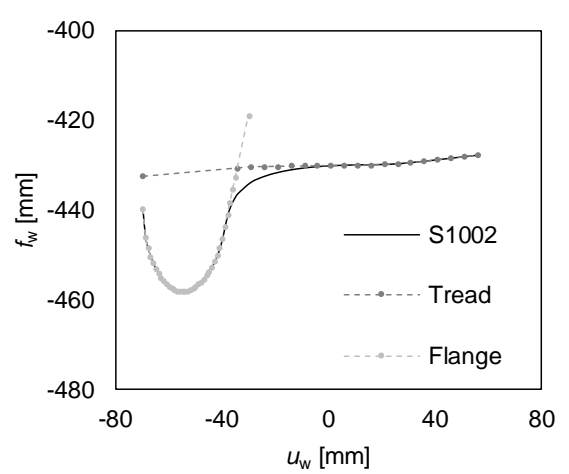

(a)

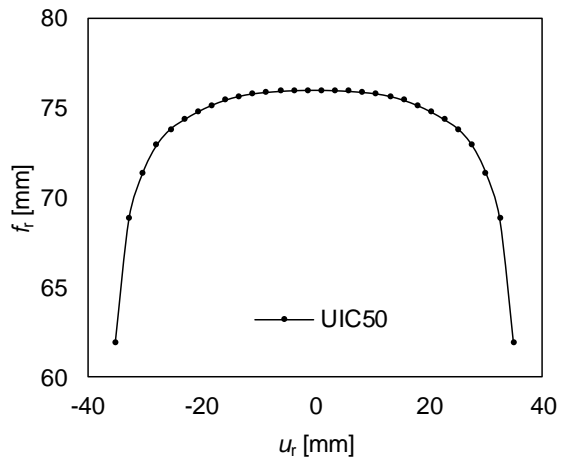

(b)

Fig. 9: (a) Tread and flange profiles that represent the wheel S1002 and (b) rail profile that represents the rail UIC50

\subsection{Contact Analysis}

The contact analysis serves to study the contact conditions of different wheel-rail interactions. In the static analysis, the wheelset is kept centred with the track, being prescribed its height and its relative motion with respect to the track to reach specified normal and creep forces. Quantities, such as, the contact patch, maximum normal pressure and creep forces are evaluated with the CONTACT software and with the non-Hertzian and Hertzian models presented in this work. A discussion addressing the comparison of results obtained and the influence of selected input parameters is carried hereafter.

The CONTACT formulation used in this work is described in reference [82]. Briefly, the inputs for the CONTACT software are: the undeformed distance function, which is determined with the non-Hertzian contact method, the refinement for the discretization of the contact patch, namely, $\Delta x$ and $\Delta y$ that are set equal to $\Delta s$, the creepages that are determined using the procedure described in section 4.3, and the material properties $G$ and $\mu$ that are listed in Tab. 4.

\subsubsection{Normal Problem}

In order to assess the normal contact, three wheel-rail interactions are considered, in which a wheelset, a bogie and a vehicle run in a track with no initial lateral misalignment with respect to the track centreline. To represent such scenarios, the wheelset height is prescribed such that the normal force is similar to the weights per wheel, listed in Tab. 4. In addition, the parameter $\Delta s$ is tested for the values $0.1,0.2$ and $0.3 \mathrm{~mm}$, while the parameter $\Delta \theta$ is tested for the values $10^{\circ}, 5^{\circ}$ and $2.5^{\circ}$. These values, which span a wide area of applications, are selected based on the experience gained in this work. For each case study, the wheelset height is adjusted, with exception for the cases that use the non-Hertzian method, namely, when $\Delta \theta$ is $5.0^{\circ}$ and $2.5^{\circ}$, the wheelset height corresponds to the height considered in case $\Delta \theta=10^{\circ}$. This exception allows to study the impact of $\Delta \theta$ on the normal force, $N$. 

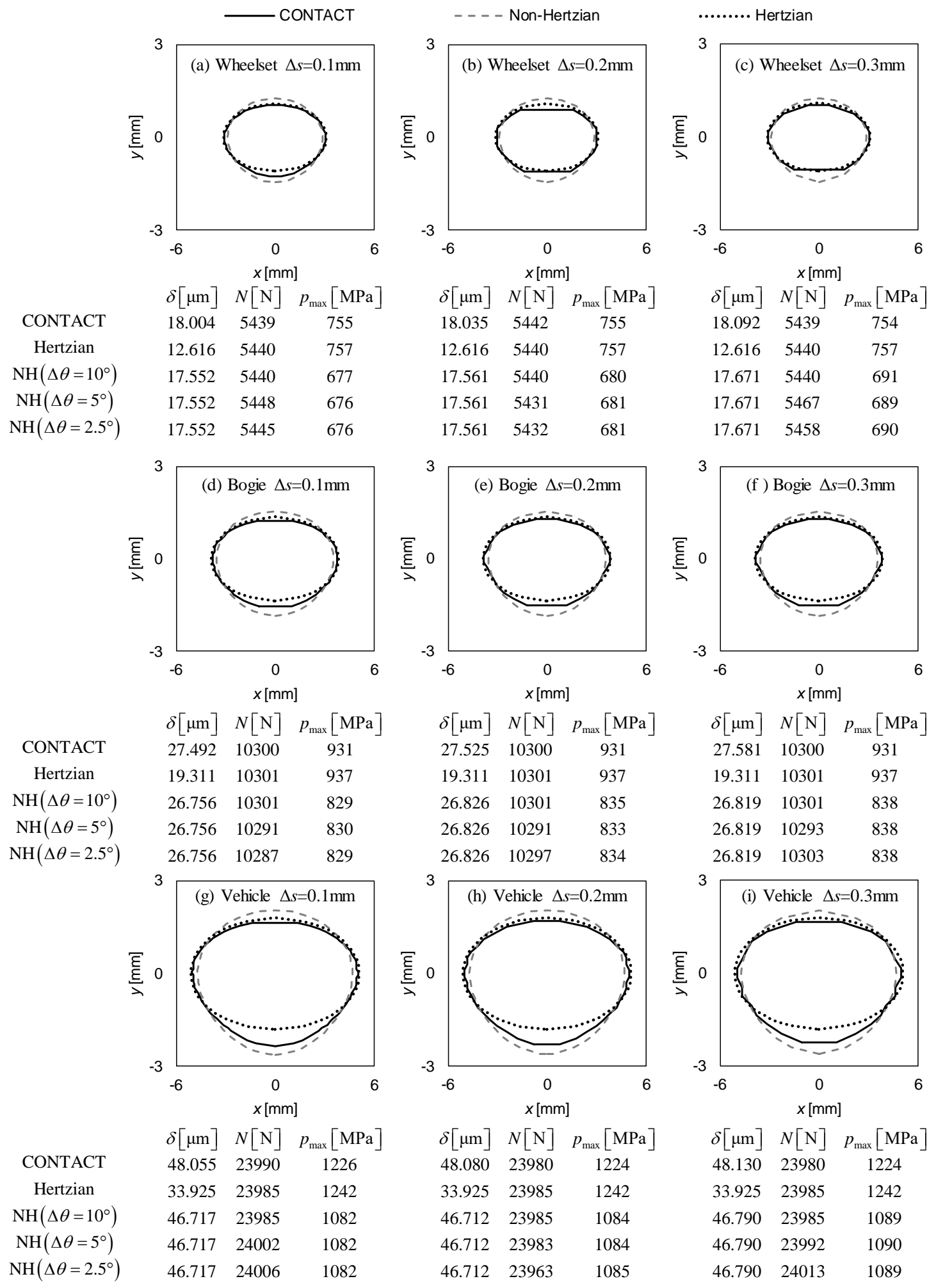

Fig. 10: Contacting areas obtained from the CONTACT, non-Hertzian and Hertzian contact models

Simulations have been carried out, with the different methodologies, namely: 9 simulations with CONTACT; 27 with the Non-Hertzian method; and 3 simulations with the Hertzian method. The results of these simulations are shown in Fig. 10 where the contact patches, the pseudo-penetration, normal force and maximum normal pressure are presented. Fig. 10 shows that the contact patch size is proportional to the normal force. The 
contact patches obtained with CONTACT, non-Hertzian and Hertzian exhibit similar contact areas. The nonelliptic shapes obtained with CONTACT and from the Non-Hertzian model are identical to the SDEC shape presented in section 6.2. Generally, the contact patch obtained with CONTACT is larger in the $x$ direction and shorter in the $y$ direction when compared with the shape obtained with the non-Hertzian method.

The pseudo-penetrations $\delta$ obtained with CONTACT and with the Non-Hertzian are similar, not deviating more than $0.7 \mu \mathrm{m}$. For the Hertzian method, lower penetrations than those obtained with CONTACT are observed. In particular, a decrease of 4,8 and $14 \mu \mathrm{m}$ in the penetration for the wheelset, bogie and vehicle case studies, respectively, are observed. The larger deviations are due to the Hertzian model being stiffer. Regarding the maximum normal pressure, CONTACT and the Hertzian method are in a good agreement, while the nonHertzian contact method exhibits values about $10 \%$ lower in all cases. This is due to the larger contact patches obtained from the non-Hertzian method, thus requiring lower pressure for the same contact force.

The variation of parameter $\Delta s$ requires an adjustment of the pseudo-penetration to maintain the normal load similar. Since the CONTACT software exploits a discretisation of the contact area, it is not possible to reach exactly a specified normal force by adjusting the pseudo-penetration. However, the maximum deviation from the force of reference is about $5 \mathrm{~N}$, as observed in Fig. 10. On the contrary, the non-Hertzian method can reach any normal force by adjusting the pseudo-penetration. Although the contact patch is discretized by strips, the width of the strips in the extremities of the contact area can vary and hence the continuity of the normal force as function of the pseudo-penetration is ensured. When the limiting strips, shown in Fig. 6(b), are not considered, the continuity of the contact patch is not ensured during the dynamic simulation, leading to numerical instabilities and hence degradation of the dynamic response.

The effect of parameter $\Delta \theta$ can be assessed by comparing the normal loads obtained from the non-Hertzian method. Here, the same pseudo-penetration is considered for all values of $\Delta \theta$. From the results shown in Fig. 10, the largest scatter obtained among, the different values for the normal load, is $28 \mathrm{~N}$. The amount of the scatter can be considered negligible, compared to the reference value provided by the non-Hertzian model with $\Delta \theta=10^{\circ}$, which is $23985 \mathrm{~N}$.

\subsubsection{Tangential Problem}

Different relative motions between the wheel and rail are tested to analyse the creep forces. Thus, for the wheel-rail interference described in Fig. 10, three different states of the wheel are considered, as described in Tab. 5. The longitudinal and lateral velocities, $V_{\mathrm{x}}$ and $V_{\mathrm{y}}$, and the pitch and yaw angular velocities, $\omega_{\mathrm{y}}$ and $\omega_{\mathrm{z}}$, are varied according to three combinations and the resulting creepages are listed in Tab. 5. In each case study, one single creepage component is emphasized. Note that the spin creepage is not zero in the longitudinal and lateral slip cases since the normal vector of the contacting surface is not perpendicular to the axis of the wheelset. Here, $\beta$ is a prescribed parameter to promote the slip, in particular, positive values, increase the creepage in study. Parameters $R$ and $H^{*}$ are listed in Tab. 4.

\begin{tabular}{|l|l|l|l|l|l|l|l|l|}
\hline Case study & $\beta$ & $\begin{array}{l}V_{\mathrm{x}} \\
{[\mathrm{m} / \mathrm{s}]}\end{array}$ & $\begin{array}{l}V_{\mathrm{y}} \\
{[\mathrm{m} / \mathrm{s}]}\end{array}$ & $\begin{array}{l}\omega_{\mathrm{y}} \\
{[\mathrm{rad} / \mathrm{s}]}\end{array}$ & $\begin{array}{l}\omega_{z} \\
{[\mathrm{rad} / \mathrm{s}]}\end{array}$ & $v_{x}$ & $v_{y}$ & $\varphi$ \\
\hline Longitudinal slip & 0.000770 & 10 & 0 & $(1+\beta) V_{\mathrm{x}} / R$ & 0 & -0.00077 & 0.00000 & -0.01983 \\
\hline Lateral slip & 0.000745 & 10 & $-\beta V_{\mathrm{x}}$ & $V_{\mathrm{x}} / R$ & 0 & 0.00000 & -0.00074 & -0.01981 \\
\hline Spin slip & 0.396000 & 10 & 0 & $(1+\beta) V_{\mathrm{x}} / R$ & $-\beta V_{\mathrm{x}} / H^{*}$ & 0.00000 & 0.00000 & -0.54706 \\
\hline
\end{tabular}

Tab. 5: Motions of the wheelset to emphasize longitudinal, lateral and spin creepages, one at a time

The results obtained from the longitudinal, lateral and spin slip case studies are shown in Fig. 11, Fig. 12 and Fig. 13, respectively. The creep forces obtained from CONTACT with $\Delta s=0.1 \mathrm{~mm}$ are given in absolute values, whereas the creep forces of the other simulations are given in relative errors defined as: 


$$
\Delta F_{\mathrm{x}}=\frac{F_{\mathrm{x}, \text { ref }}-F_{x, \text { sim }}}{F_{\mathrm{x}, \text { ref }}}, \Delta F_{\mathrm{y}}=\frac{F_{\mathrm{y}, \text { ref }}-F_{\mathrm{y}, \text { sim }}}{F_{\mathrm{y}, \text { ref }}}, \Delta M_{\mathrm{z}}=\frac{M_{\mathrm{z}, \text { ref }}-M_{\mathrm{z}, \text { sim }}}{M_{\mathrm{z}, \text { ref }}}
$$

where $F_{\mathrm{x}, \text { ref }}, F_{\mathrm{y}, \text { ref }}$ and $M_{\mathrm{z} \text {,ref }}$ refer to the creep forces obtained from CONTACT with $\Delta s=0.1 \mathrm{~mm}$, while $F_{\mathrm{x}, \text { sim }}$, $F_{\mathrm{y}, \text { sim }}$ and $M_{\mathrm{z}, \text { sim }}$ refer to the creep forces obtained from another simulation, sim. In Fig. 11, Fig. 12 and Fig. 13, the maximum absolute relative error for each force in each case study is also given. There, the grey band plotted in each column are related to the relative errors. Bars directed to the left correspond to negative values, whereas bars directed to the right refer to positive values, and the largest bar observed in each column refers to the highest relative error in absolute terms.

\begin{tabular}{|c|c|c|c|c|c|c|c|c|c|}
\hline \multicolumn{10}{|c|}{ Creep forces obtained from simulation of reference } \\
\hline Case Study & \multicolumn{3}{|c|}{ Wheelset } & \multicolumn{3}{|c|}{ Bogie } & \multicolumn{3}{|c|}{ Vehicle } \\
\hline Simulation of reference & $F_{\mathrm{x}}[\mathrm{kN}]$ & $F_{\mathrm{y}}[\mathrm{kN}]$ & $M_{\mathrm{z}}[\mathrm{Nm}]$ & $F_{\mathrm{x}}[\mathrm{kN}]$ & $F_{\mathrm{y}}[\mathrm{kN}]$ & $M_{\mathrm{z}}[\mathrm{Nm}]$ & $F_{\mathrm{x}}[\mathrm{kN}]$ & $F_{\mathrm{y}}[\mathrm{kN}]$ & $M_{\mathrm{z}}[\mathrm{Nm}]$ \\
\hline CONTACT $\Delta s=0.1 \mathrm{~mm}$ & 1.002 & 0.034 & 0.063 & 1.622 & 0.067 & 0.152 & 3.023 & 0.159 & 0.518 \\
\hline \multicolumn{10}{|c|}{ Relative errors with respect to the simulation of reference } \\
\hline Case Study & \multicolumn{3}{|c|}{ Wheelset } & \multicolumn{3}{|c|}{ Bogie } & \multicolumn{3}{|c|}{ Vehicle } \\
\hline Comparative simulations & $\Delta F_{\mathrm{x}}[\%]$ & $\Delta F_{\mathrm{y}}[\%]$ & $\Delta M_{\mathrm{z}}[\%]$ & $\Delta F_{\mathrm{x}}[\%]$ & $\Delta F_{\mathrm{y}}[\%]$ & $\Delta M_{\mathrm{z}}[\%]$ & $\Delta F_{\mathrm{x}}[\%]$ & $\Delta F_{\mathrm{y}}[\%]$ & $\Delta M_{\mathrm{z}}[\%]$ \\
\hline CONTACT $\Delta s=0.2 \mathrm{~mm}$ & -0.6 & -1.4 & -6.5 & -0.7 & -1.0 & -5.0 & -0.8 & -1.6 & -2.8 \\
\hline$\Delta s=0.3 \mathrm{~mm}$ & -3.6 & -6.0 & -9.9 & -1.5 & -2.8 & -10.6 & -1.2 & -2.0 & -6.2 \\
\hline Hertzian & -3.6 & 91.1 & - & -4.5 & 89.3 & - & -4.4 & 86.2 & - \\
\hline$\Delta s=0.1 \mathrm{~mm}, \Delta \theta=10^{\circ}$ & 1.9 & 10.3 & -12.2 & 2.1 & 10.2 & -16.7 & 2.0 & 10.2 & -22.1 \\
\hline$\Delta s=0.1 \mathrm{~mm}, \Delta \theta=5^{\circ}$ & 1.9 & 10.3 & -12.2 & 2.1 & 10.3 & -16.6 & 2.0 & 10.2 & -22.1 \\
\hline ‡ $\Delta s=0.1 \mathrm{~mm}, \Delta \theta=2.5^{\circ}$ & 1.9 & 10.3 & -12.2 & 2.1 & 10.2 & -16.7 & 2.0 & 10.2 & -22.1 \\
\hline 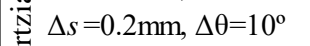 & 1.3 & 9.2 & -14.4 & 2.0 & 10.0 & -17.4 & 1.9 & 10.0 & -22.5 \\
\hline 胥 $\Delta s=0.2 \mathrm{~mm}, \Delta \theta=5^{\circ}$ & 1.3 & 9.2 & -14.4 & 1.9 & 10.0 & -17.5 & 1.9 & 10.0 & -22.5 \\
\hline ฮ $\Delta s=0.2 \mathrm{~mm}, \Delta \theta=2.5^{\circ}$ & 1.3 & 9.2 & -14.4 & 1.9 & 10.0 & -17.5 & 1.9 & 10.0 & -22.5 \\
\hline 乙 $\Delta s=0.3 \mathrm{~mm}, \Delta \theta=10^{\circ}$ & 1.5 & 9.6 & -15.0 & 1.2 & 8.8 & -19.6 & 2.4 & 10.8 & -21.6 \\
\hline$\Delta s=0.3 \mathrm{~mm}, \Delta \theta=5^{\circ}$ & 1.4 & 9.5 & -15.1 & 1.2 & 8.8 & -19.6 & 2.4 & 10.8 & -21.6 \\
\hline$\Delta s=0.3 \mathrm{~mm}, \Delta \theta=2.5^{\circ}$ & 1.4 & 9.5 & -15.1 & 1.2 & 8.8 & -19.6 & 2.4 & 10.8 & -21.6 \\
\hline Max. abs. relative error & 3.6 & 91.1 & 15.1 & 4.5 & 89.3 & 19.6 & 4.4 & 86.2 & 22.5 \\
\hline
\end{tabular}

Fig. 11: Comparison between creep forces obtained from the longitudinal slip case study described in Tab. 5

\begin{tabular}{|c|c|c|c|c|c|c|c|c|c|}
\hline \multicolumn{10}{|c|}{ Creep forces obtained from simulation of reference } \\
\hline Case Study & \multicolumn{3}{|c|}{ Wheelset } & \multicolumn{3}{|c|}{ Bogie } & \multicolumn{3}{|c|}{ Vehicle } \\
\hline Simulation of reference & $F_{\mathrm{x}}[\mathrm{kN}]$ & $F_{\mathrm{y}}[\mathrm{kN}]$ & $M_{\mathrm{z}}[\mathrm{Nm}]$ & $F_{\mathrm{x}}[\mathrm{kN}]$ & $F_{\mathrm{y}}[\mathrm{kN}]$ & $M_{\mathrm{z}}[\mathrm{Nm}]$ & $F_{\mathrm{x}}[\mathrm{kN}]$ & $F_{\mathrm{y}}[\mathrm{kN}]$ & $M_{\mathrm{z}}[\mathrm{Nm}]$ \\
\hline CONTACT $\Delta s=0.1 \mathrm{~mm}$ & 0.000 & 1.001 & -0.561 & 0.001 & 1.626 & -1.294 & 0.007 & 3.045 & -3.626 \\
\hline \multicolumn{10}{|c|}{ Relative errors with respect to the simulation of reference } \\
\hline Case Study & \multicolumn{3}{|c|}{ Wheelset } & \multicolumn{3}{|c|}{ Bogie } & \multicolumn{3}{|c|}{ Vehicle } \\
\hline Comparative simulations & $\Delta F_{\mathrm{x}}[\%]$ & $\Delta F_{\mathrm{y}}[\%]$ & $\Delta M_{\mathrm{z}}[\%]$ & $\Delta F_{\mathrm{x}}[\%]$ & $\Delta F_{\mathrm{y}}[\%]$ & $\Delta M_{\mathrm{z}}[\%]$ & $\Delta F_{\mathrm{x}}[\%]$ & $\Delta F_{\mathrm{y}}[\%]$ & $\Delta M_{\mathrm{z}}[\%]$ \\
\hline \multirow{2}{*}{$\begin{aligned} \text { CONTACT } & \Delta s=0.2 \mathrm{~mm} \\
& \Delta s=0.3 \mathrm{~mm}\end{aligned}$} & -199.0 & -0.5 & 1.0 & -17.8 & -0.6 & 1.1 & -6.7 & -1.0 & 1.0 \\
\hline & 195.9 & -3.4 & 6.2 & -121.7 & -1.4 & 2.2 & -37.2 & -1.3 & 1.4 \\
\hline Hertzian & 99.7 & -2.0 & - & 100.0 & -3.1 & - & 100.2 & -3.7 & - \\
\hline \multirow{2}{*}{$\begin{aligned} \Delta s & =0.1 \mathrm{~mm}, \Delta \theta=10^{\circ} \\
\Delta s & =0.1 \mathrm{~mm}, \Delta \theta=5^{\circ}\end{aligned}$} & -116.8 & 4.8 & 6.4 & -127.5 & 4.4 & 7.5 & -76.0 & 4.1 & 8.6 \\
\hline & -117.1 & 4.8 & 6.3 & -127.3 & 4.4 & 7.6 & -76.1 & 4.0 & 8.6 \\
\hline \multirow{5}{*}{ 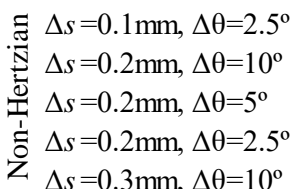 } & -117.0 & 4.8 & 6.3 & -127.4 & 4.4 & 7.5 & -76.1 & 4.0 & 8.6 \\
\hline & -120.5 & 4.1 & 6.0 & -128.9 & 4.3 & 7.4 & -76.7 & 3.9 & 8.5 \\
\hline & -120.2 & 4.2 & 6.1 & -129.2 & 4.2 & 7.2 & -76.7 & 3.9 & 8.5 \\
\hline & -120.3 & 4.2 & 6.1 & -129.1 & 4.2 & 7.2 & -76.6 & 3.9 & 8.6 \\
\hline & -122.2 & 4.4 & 6.1 & -132.7 & 3.5 & 6.6 & -75.5 & 4.4 & 8.9 \\
\hline \multirow{2}{*}{$\begin{aligned} \text { 乙 } & =0.3 \mathrm{~mm}, \Delta \theta=10^{\circ} \\
\Delta s & =0.3 \mathrm{~mm}, \Delta \theta=5^{\circ} \\
\Delta s & =0.3 \mathrm{~mm}, \Delta \theta=2.5^{\circ}\end{aligned}$} & -123.2 & 4.3 & 5.7 & -132.6 & 3.5 & 6.6 & -75.6 & 4.4 & 8.9 \\
\hline & -122.9 & 4.3 & 5.8 & -132.7 & 3.5 & 6.6 & -75.6 & 4.4 & 8.9 \\
\hline Max. abs. relative error & 199.0 & 4.8 & 6.4 & 132.7 & 4.4 & 7.6 & 100.2 & 4.4 & 8.9 \\
\hline
\end{tabular}

Fig. 12: Comparison between creep forces obtained from the lateral slip case study described in Tab. 5 
In general, the spin creep moments are negligible for all cases considered in this work, being null for the Hertzian method, since the spin moment is neglected in the Polach model [69]. In turn, high relative errors are observed. For instance, Fig. 12 shows an error of $199.0 \%$ for the longitudinal creep force, nevertheless, these forces are very low compared with the lateral creep forces. Thus, special attention is put in the deviation of the creep forces that show higher absolute values, with particular focus on the longitudinal creep forces shown in Fig. 11 and on the lateral creep forces shown in Fig. 12 and Fig. 13. In these cases, it must be noted that: $(i)$ the relative errors obtained from the wheelset, bogie and vehicle case studies are similar, meaning that the normal load has a small impact on the relative errors of the creep forces; (ii) for the longitudinal and lateral slip, the Hertzian method shows the higher absolute relative errors of $4.5 \%$ and $3.7 \%$, respectively, while for the spin slip case, the non-Hertzian contact reaches an absolute error of 14.8\%; (iii) the parameter $\Delta \theta$ does not have much influence on the deviations of the creep forces, meaning that, increasing $\Delta \theta$ up to $10^{\circ}$ does not degrade the results; (iv) increasing the parameter $\Delta s$ can degrade significantly the accuracy of the results obtained from CONTACT, as shown in Fig. 11, namely, the deviation increases from $0.6 \%$ to $3.6 \%$ when $\Delta s$ is increased from 0.2 up to $0.3 \mathrm{~mm}$. Nevertheless, in the non-Hertzian method, the increase of $\Delta s$ from 0.1 to $0.3 \mathrm{~mm}$ has no significant impact.

\begin{tabular}{|c|c|c|c|c|c|c|c|c|c|}
\hline \multicolumn{10}{|c|}{ Creep forces obtained from simulation of reference } \\
\hline Case Study & \multicolumn{3}{|c|}{ Wheelset } & \multicolumn{3}{|c|}{ Bogie } & \multicolumn{3}{|c|}{ Vehicle } \\
\hline Simulation of reference & $F_{\mathrm{x}}[\mathrm{kN}]$ & $F_{\mathrm{y}}[\mathrm{kN}]$ & $M_{\mathrm{z}}[\mathrm{Nm}]$ & $F_{\mathrm{x}}[\mathrm{kN}]$ & $F_{\mathrm{y}}[\mathrm{kN}]$ & $M_{\mathrm{z}}[\mathrm{Nm}]$ & $F_{\mathrm{x}}[\mathrm{kN}]$ & $F_{\mathrm{y}}[\mathrm{kN}]$ & $M_{\mathrm{z}}[\mathrm{Nm}]$ \\
\hline CONTACT $\Delta s=0.1 \mathrm{~mm}$ & 0.032 & 1.000 & 0.369 & 0.075 & 1.898 & 0.879 & 0.239 & 4.394 & 2.812 \\
\hline \multicolumn{10}{|c|}{ Relative errors with respect to the simulation of reference } \\
\hline Case Study & \multicolumn{3}{|c|}{ Wheelset } & \multicolumn{3}{|c|}{ Bogie } & \multicolumn{3}{|c|}{ Vehicle } \\
\hline Comparative simulations & $\Delta F_{\mathrm{x}}[\%]$ & $\Delta F_{\mathrm{y}}[\%]$ & $\Delta M_{\mathrm{z}}[\%]$ & $\Delta F_{\mathrm{x}}[\%]$ & $\Delta F_{\mathrm{y}}[\%]$ & $\Delta M_{\mathrm{z}}[\%]$ & $\Delta F_{\mathrm{x}}[\%]$ & $\Delta F_{\mathrm{y}}[\%]$ & $\Delta M_{\mathrm{z}}[\%]$ \\
\hline \multirow{2}{*}{$\begin{aligned} & \text { CONTACT } \Delta s=0.2 \mathrm{~mm} \\
& \Delta s=0.3 \mathrm{~mm} \\
&\end{aligned}$} & -5.8 & 0.9 & -6.4 & -1.9 & 1.3 & -4.9 & -2.4 & 0.6 & -4.0 \\
\hline & -11.7 & 2.4 & -15.3 & -5.5 & 2.6 & -9.5 & -3.2 & 1.5 & -6.8 \\
\hline \multirow{10}{*}{ 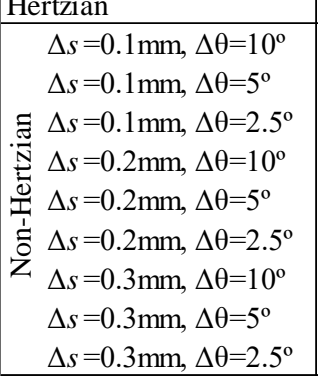 } & 99.9 & 6.8 & - & 100.0 & 7.0 & - & 100.1 & 6.5 & - \\
\hline & -7.8 & 14.8 & -30.1 & -33.8 & 14.3 & -30.3 & -37.4 & 12.6 & -30.8 \\
\hline & -7.9 & 14.8 & -30.1 & -33.8 & 14.3 & -30.3 & -37.4 & 12.6 & -30.8 \\
\hline & -7.9 & 14.8 & -30.1 & -33.8 & 14.3 & -30.3 & -37.4 & 12.6 & -30.8 \\
\hline & -9.7 & 13.9 & -32.5 & -34.6 & 14.0 & -30.8 & -37.8 & 12.4 & -31.1 \\
\hline & -9.6 & 13.9 & -32.5 & -34.8 & 14.0 & -30.8 & -37.8 & 12.4 & -31.1 \\
\hline & -9.6 & 13.9 & -32.5 & -34.7 & 14.0 & -30.8 & -37.8 & 12.4 & -31.1 \\
\hline & -10.8 & 14.2 & -31.6 & -36.5 & 13.0 & -33.4 & -37.3 & 13.1 & -29.5 \\
\hline & -11.0 & 14.1 & -31.5 & -36.5 & 13.0 & -33.4 & -37.3 & 13.1 & -29.5 \\
\hline & -10.9 & 14.1 & -31.5 & -36.5 & 13.0 & -33.4 & -37.3 & 13.1 & -29.5 \\
\hline Max. abs. relative error & 99.9 & 14.8 & 32.5 & 100.0 & 14.3 & 33.4 & 100.1 & 13.1 & 31.1 \\
\hline
\end{tabular}

Fig. 13: Comparison between creep forces obtained from the spin slip case study described in Tab. 5

\subsection{Dynamic Analysis}

The non-Hertzian and Hertzian methods are considered in the multibody simulations that represent three case scenarios: a wheelset negotiating a tangent track; a bogie negotiating a tangent track; and a vehicle negotiating a curved track with the geometry shown in Fig. 14. In all cases, an initial lateral misalignment of 2 $\mathrm{mm}$ is considered to promote the hunting motion, while the height of the bodies is adjusted so that no wheel-rail contact exist in the beginning of the simulation. Thus, these simulations are characterized by a first period in which the wheels fall over the track and, due to the lateral misalignment, the wheel-rail contact is initiated in the left wheels and then in the right wheels. The initial longitudinal speed for the wheelset in case scenario 1 is 10 $\mathrm{m} / \mathrm{s}$, while in case scenarios 2 and 3 the initial longitudinal velocity of the bogie/vehicle is $18.3 \mathrm{~m} / \mathrm{s}$. The initial rolling angular speed of the wheelsets is defined according to the longitudinal speed and wheel nominal radius. The multibody code is implemented in MATLAB, in which the 'ode15s' solver is used for the numerical integration with a maximum integration step size of $10^{-4} \mathrm{~s}$, being the absolute and relative tolerance errors equal 
to $10^{-7} \mathrm{~s}$ and $10^{-7}$, respectively. The results are reported with a sampling frequency of $200 \mathrm{~Hz}$. The simulation times for the tangent and curved track scenarios are 10 and $41 \mathrm{~s}$, respectively.

\subsubsection{Efficiency and accuracy analysis}

The non-Hertzian contact model presented in this work requires the selection of parameters $\Delta s$ and $\Delta \theta$ to determine the undeformed distance function, which is illustrated in Fig. 6, and to discretize the contact area, as shown in Fig. 7(b). Since parameters $\Delta s$ and $\Delta \theta$ impact the accuracy of the solution and the computational cost, a batch of simulations has been performed considering several combinations of $\Delta s$ and $\Delta \theta$. The simulations performed in this analysis consider the bogie negotiating a tangent track.

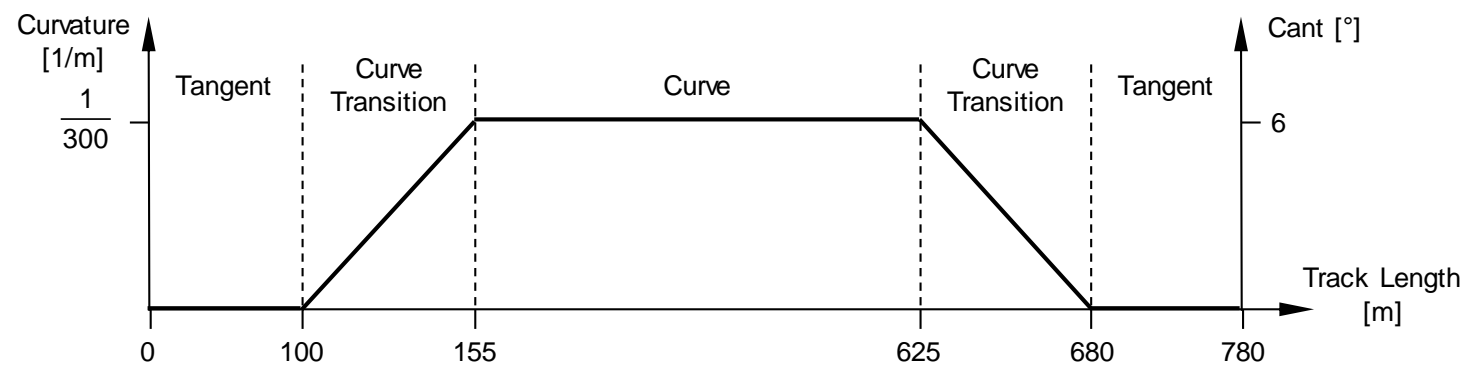

Fig. 14: Curvature and cant angle of the curved track

To analyse the simulations in terms of computational cost and accuracy, the computational time of the simulation and the normal contact force of the left leading wheel, are used. Here, the Hertzian method is also considered in this batch of simulations only to compare the computational effort with respect to the non-Hertzian method. In addition, the impact of considering dissipation in the normal contact is assessed by setting parameter $e$ to values 1 and 0.75 in different simulations of the same test case. Thus, the time and error ratios are assessed by:

$$
t_{\text {ratio }}=\frac{t_{\text {sim }}}{t_{\text {fastest }}}, \quad e r r o r_{\text {ratio }}=\frac{\int\left|N_{\text {sim }}(t)-N_{\text {ref }}(t)\right| \mathrm{d} t}{\int\left|N_{\text {max }}-N_{\text {ref }}\right| \mathrm{d} t}
$$

where $t_{\text {sim }}$ is the computational time of simulation $\operatorname{sim}$; $t_{\text {fastest }}$ is the lowest computational time obtained from this batch of simulations; $N_{\text {sim }}$ is the normal force obtained from simulation $\operatorname{sim} ; N_{\text {ref }}$ is the normal force obtained from simulation of reference; and $N_{\max }$ is the normal force of simulation that shows lower accuracy with respect to the simulation of reference. The normal forces are reported to the left wheel of the leading wheelset, i.e., to the outer wheel when negotiating the curve, and the simulation of reference is the one that utilizes the nonHertzian method with $\Delta s=0.1 \mathrm{~mm}$ and $\Delta \theta=2.5^{\circ}$, which corresponds to the more refined combination. Despite of a good agreement between the results obtained for the cases that use the non-Hertzian method, the calculation of error $_{\text {ratio }}$ allows to sort the applications by accuracy.

Fig. 15 shows the time ratio and error ratios, being bars plotted in each column related to the magnitude of the obtained values. From these results, the non-Hertzian method shows to be 2.6 to 8.0 times slower compared to the Hertzian method. The use of damping in the normal contact decreases slightly the computational cost. The parameters $\Delta s$ and $\Delta \theta$ show a significant impact on the time ratio, namely, higher values lead to slower simulations. In turn, an increase of these parameters leads to a higher error ratio as shown in Fig. 15. Note that $\Delta s=0.3 \mathrm{~mm}$ exhibits error ratios much higher when compared with the others. Among the simulations performed, the combination $\Delta s=0.2 \mathrm{~mm}$ and $\Delta \theta=5^{\circ}$ is selected as the best trade-off between efficiency and accuracy. 


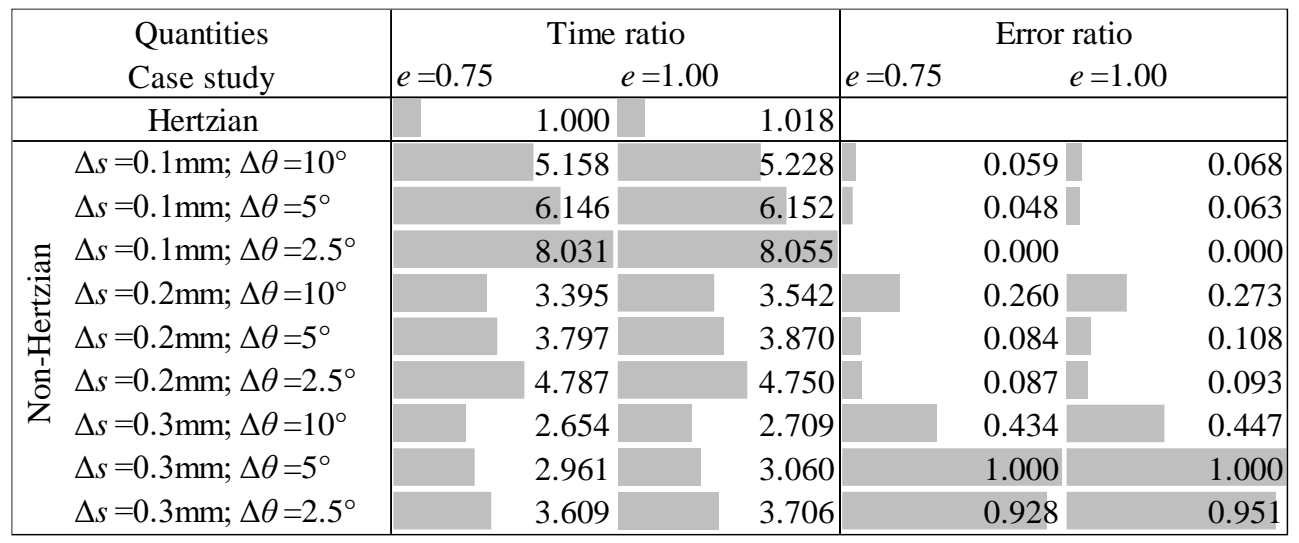

Fig. 15: Time and error ratio of the batch of simulations that consider the bogie negotiates a tangent track for elastic wheel-rail contact, $e=1$, and slightly damped contact, $e=0.75$

\subsubsection{Wheelset negotiating a tangent track}

The normal force of the left wheel tread is shown in Fig. 16. Since the wheelset lands in the track, impacts of the wheel with the rail are observed in the first period of the simulation, which lead to high normal contact force when compared to the weight per wheel. The initial part of the simulation, when the wheels falls over the track, does not correspond to any realistic condition and is used only to initialise the model simulation being the results obtained during the stabilization period not considered. When $e=1$, the stabilization period is $0.8 \mathrm{~s}$ while a shorter period of $0.3 \mathrm{~s}$ is observed when $e=0.75$. After the stabilization period, the normal contact force exhibits high frequency varying between 0.5 and $13 \mathrm{kN}$ when $e=1$, as shown in Fig. 16(a). In turn, a nearly constant force similar to the weight per wheel of $5.4 \mathrm{kN}$ is observed in Fig. 16(b) where $e=0.75$. The hunting motion of the wheelset is related with the oscillatory motion of the normal contact force, observed in the detailed graphic shown in Fig. 16 (b). Thus, it is demonstrated the importance of considering energy dissipation in the normal load, represented by the restitution coefficient $e<1$, which not only reduces the computational cost but also smooths the contact forces.

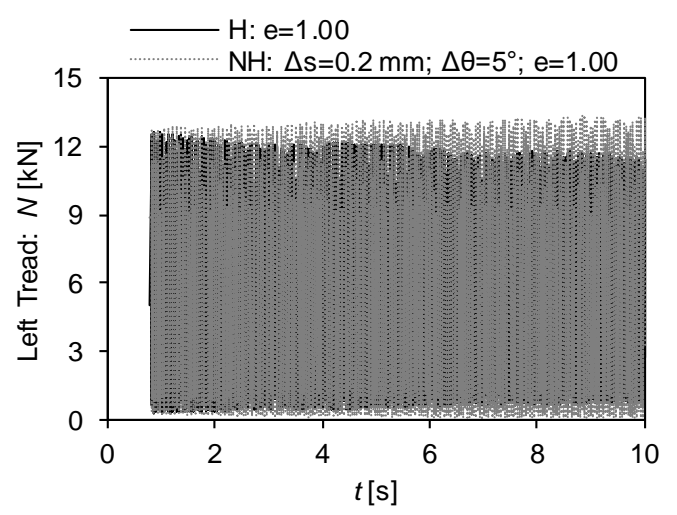

(a)

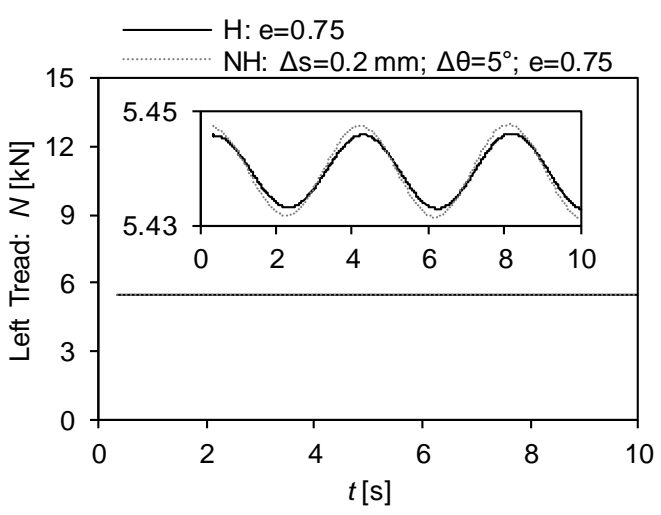

(b)

Fig. 16: Normal contact forces of the left tread obtained from the simulations that represent the wheelset negotiating a tangent track, (a) when the dissipation is neglected, $e=1$, and (b) when dissipation is considered, $e=0.75$

\subsubsection{Bogie negotiating a tangent track}

In the case of the dynamics of a bogie, the stabilization of the contact in the wheel-rail contact model occurs even when no energy dissipation is considered in the normal contact, as shown in Fig. 17(a). In this case, the stabilization is ensured by the energy dissipation performed of the primary suspension by vertical dampers that 
constrain the motion of the wheelset. In addition, the parameter $e$ does not play a key role, as it can be observed from the results shown in Fig. 17(a) and Fig. 17(b). Also, the non-Hertzian model shows a slightly higher amplitude of the normal force comparing with the Hertzian model, which can be due to the lateral motion of the wheelsets, as shown in Fig. 18. The small difference of the wheelset motion obtained with the non-Hertzian and Hertzian methods is caused using different tangential contact models.

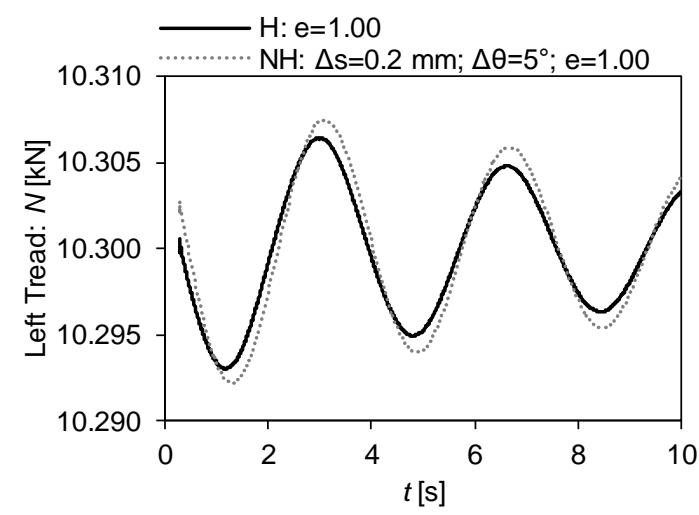

(a)

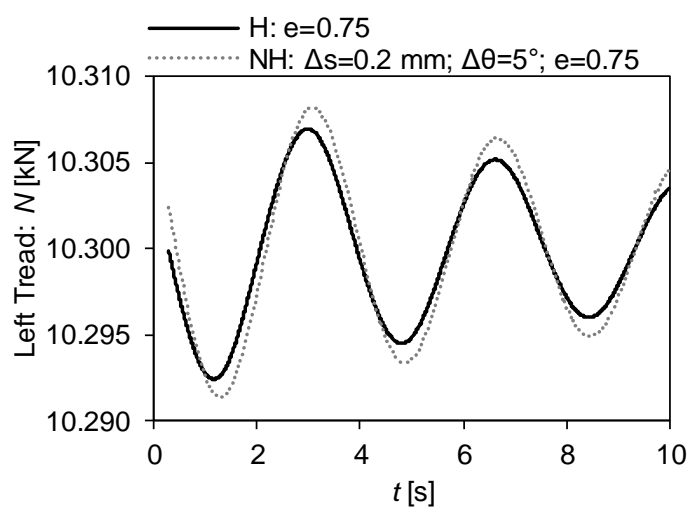

(b)

Fig. 17: Normal contact forces of the left tread obtained from the simulations that represent the bogie negotiating a tangent track, (a) when the dissipation is neglected, $e=1$, and (b) when dissipation is considered, $e=0.75$

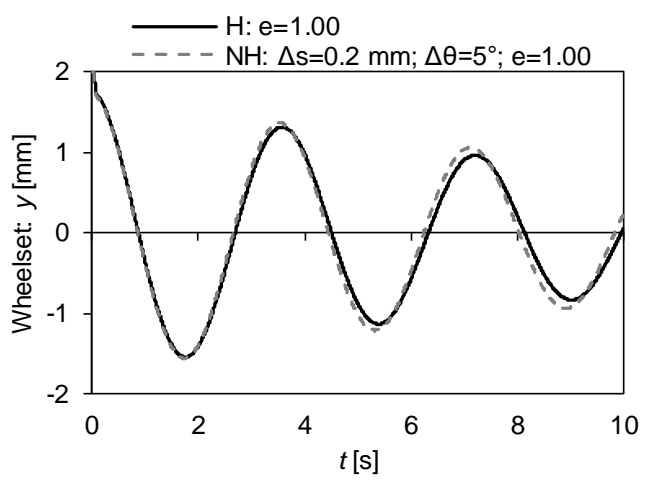

(a)

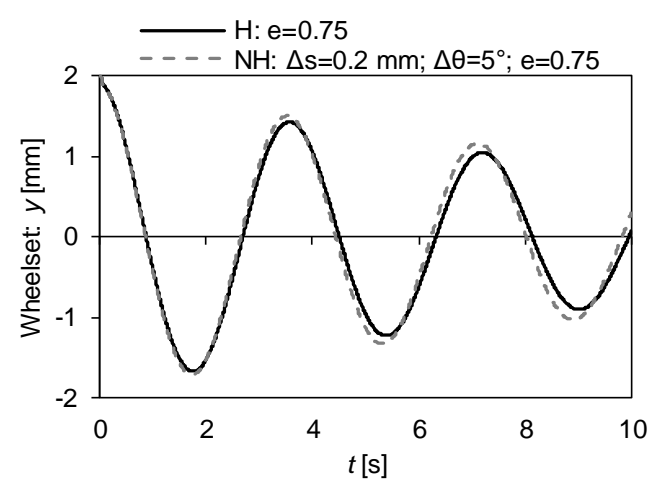

(b)

Fig. 18: Lateral motion of the leading wheelset obtained from the simulations that represent the bogie negotiating a tangent track, (a) when the dissipation is neglected, $e=1$, and (b) when dissipation is considered, $e=0.75$

\subsubsection{Vehicle negotiating a curved track}

In the curve negotiation scenario, tread and flange contacts are expected to occur simultaneously in the outer wheels. To assess the impact of the simplification in the wheel profile, the contacting points in the tread and flange are shown in Fig. 19. This result is obtained from the simulation that considers the Hertzian method with $e=0.75$, however, a similar result is obtained from the other simulations that represent this case study. Fig. 19 shows that the points of contact in the tread span the portion of the profile ranging from $u_{\mathrm{w}}=5.5 \mathrm{~mm}$ to $u_{\mathrm{w}}=18.0$ $\mathrm{mm}$, whereas the contact in the flange occurs around $u_{\mathrm{w}}=-38 \mathrm{~mm}$. Here, the tread and flange profiles represent well the S1002 wheel profile, since the contact points lie in segments where the real and simplified profiles are equal or very similar, as shown in Fig. 19.

In a curve negotiation, the flange contact is observed especially in the outer wheels. Fig. 20 shows the normal contact forces in the flange contact in the leading wheelset of the front bogie. These results are obtained with the Hertzian and non-Hertzian models in which parameter $e$ is set equal to 1 and 0.75 . In both simulations, a sudden increase of the normal contact force is observed when the flange contact initiates, which indicates the beginning of the curve negotiation. Then, another sudden variation of the normal contact force occurs at $t=8.3 \mathrm{~s}$ 
which is related to the initiation of the flange contact in the leading wheelset of the rear bogie. Note that, due to the suspension system of the vehicle, only the leading wheelsets of each bogie exhibit the flange contact during the whole curve negotiation. It is worth noting that the normal contact force reaches a constant value of $11.2 \mathrm{kN}$, during the curve segment negotiation, which is approximately one half of the centrifugal force. A similar magnitude of the normal contact force is developed in the flange contact in the rear bogie. Thus, the equilibrium between the centrifugal force and the two flange contacts is verified. Moreover, by comparing the Hertzian and non-Hertzian models and the effect of parameter $e$, the main difference is observed when drastic variation of the normal contact force occurs.

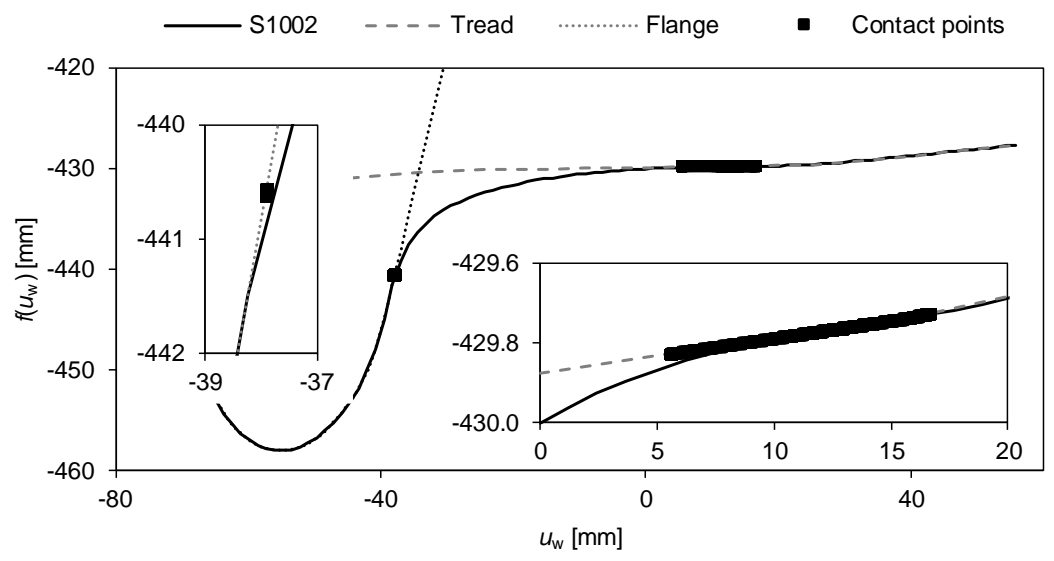

Fig. 19: Contact points in the tread and flange of the outer wheel of the leading wheelset

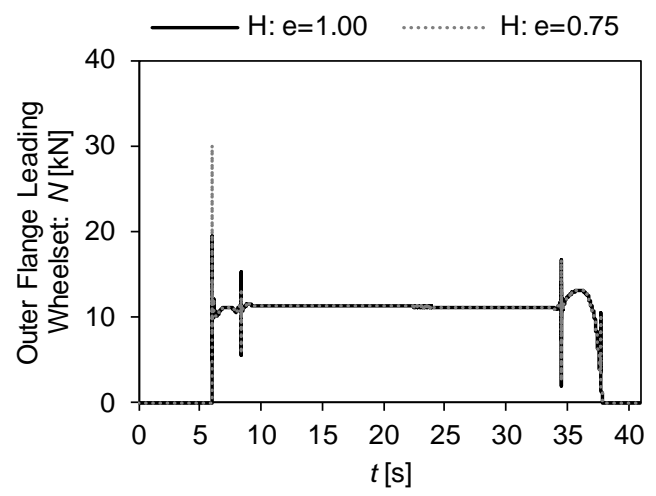

(a)

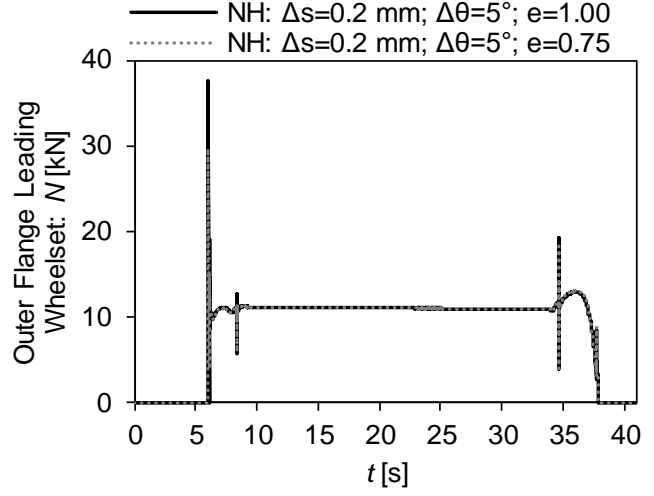

(b)

Fig. 20: Normal contact forces of the outer leading flange obtained from the simulations that represent the bogie negotiating a curved track, (a) when the Hertzian method and (b) when the non-Hertzian method are utilized

Since high creepages are expected in the flange contact due to the high angle between the normal of the contacting area and the wheel axis, the tangential contact model defined by the KBTNH is analysed. Fig. 21 shows the inputs of the KBTNH of the outer leading flange obtained from simulations that consider $e=0.75$ and $e=1$. From the analysis of these results, it is observed that the contact shape is nearly elliptical since the higher value of $\psi$ is never higher than 0.05 , in absolute terms. However, $g$ reaches values higher than 5 and, since extrapolation of the KBTNH is not considered, the input $g$ has been truncated when the boundaries of the table are exceeded. The variation of parameter $e$ has impact not only on the normal force, but also on the creepages $v$ and $\chi$, namely, in the curve transition negotiation, which can be related to variation of the velocity of penetration due to approximation and separation of the wheel and rail in the flange contact. Finally, the angle $\alpha$ reaches values around $45^{\circ}$ meaning that the longitudinal and lateral creep forces are of the same order of magnitude. 

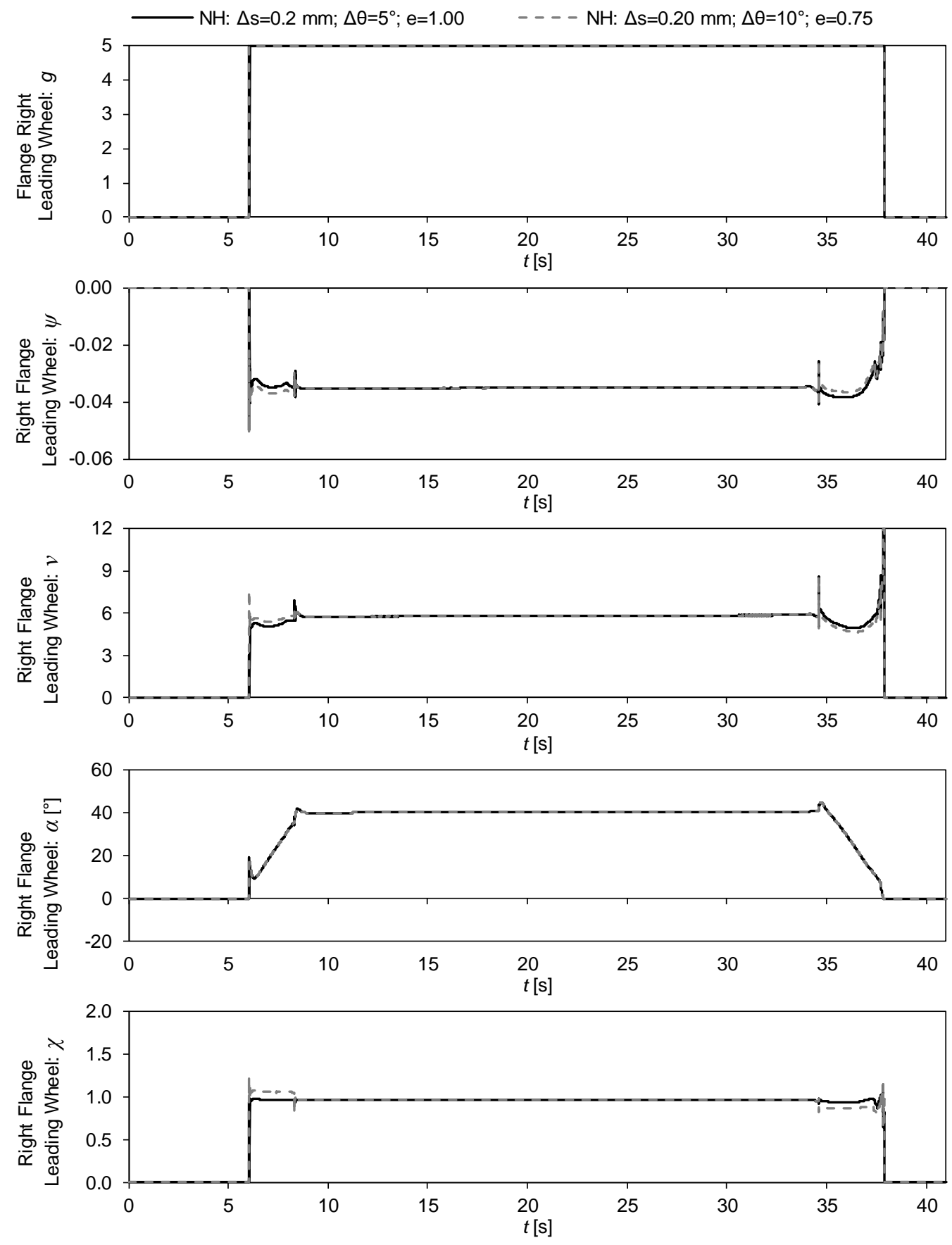

Fig. 21: Inputs of the KBTNH of the left tread obtained from simulations (a) with no damping ( $e=1)$ and (b) with damping ( $e=0.75$ )

\section{Conclusions}

A detailed description of a non-Hertzian contact model and its implementation in a multibody code is presented. The wheel-rail contact method proposed in this work consists of an enhancement of the Hertzian contact model proposed by Pombo et al. $[1,28]$ by introducing a strategy that determines the undeformed distance function and the corresponding non-elliptic contact patch. To solve the normal contact problem, the KP model has been selected [59]. In addition, the hysteresis damping considered in the LN model [62, 63], which is used in the Hertzian contact, is proposed to be introduced in the KP model. In turn, the tangential forces are estimated by interpolating the KBTNH [20,21], whereas the Polach method [69] is used for the Hertzian contact 
model. To show the impact of considering the Hertzian and non-Hertzian contact models, contact analyses and multibody simulations of selected case studies are performed, being the wheel profile S1002 and the rail UIC50 considered. For the contact analysis, the CONTACT program is also used to provide results of reference. Here, the normal contact force has been prescribed, and the differences between the three methods are analysed in detail. Comparing the contact patches obtained from CONTACT and the non-Hertzian method, it is concluded that the SDEC shape is capable of accurately reproducing the non-Hertzian contact patch, which is formed by the wheel and the rail. Thus, the KP and the KBTNH models are suitable to handle the wheel-rail contact problem considered in this work. From the multibody simulations, several conclusions have been drawn. First, the parameters of the non-Hertzian method have been selected to solve the trade-off between accuracy and computational cost, namely, the non-Hertzian method can be 2.6 to 8.0 times slower than the Hertzian contact. Second, the hysteresis damping in the normal contact plays a key role in the simulation of a wheelset negotiating a rigid track, namely, the absence of energy dissipation in the normal contact leads to a stiff problem that provides unrealistic results. For the multibody models that comprise damping in the suspension system, the dissipation in the normal contact model effect is only perceived when the flange contact initiates. Overall, this work suggests that the non-Hertzian contact model obtained combining the KP method to solve the normal problem and the KBTNH to solve the tangential problem provides numerical results that are more accurate than those obtained from traditional Hertzian contact models yet leading to an acceptable computational effort.

Future developments are suggested by the results presented in this work. First, different normal and tangential contact models can be used in the non-Hertzian method, being possible to improve the accuracy and efficiency. Second, extending the domain of the KBTNH is required since the parameter $g$ exceeds its upper limit as observed in the multibody simulations performed in this work. In turn, a different work [72] has demonstrated that the parameterization of the KBTNH domain plays a key role on the accuracy of its interpolation. Thus, the accuracy of the tangential forces obtained from this model can be improved. Third, although the non-Hertzian contact model proposed here determines non-elliptical contact patches, these are symmetry with respect to the rolling direction. The improvement of the strategy used to determine the strips of the contact area is intended to obtain non-symmetric contact patches as observed for higher yaw angles [25]. Then, the extended Kik-Piotrowski model can be applied to solve the normal contact [25], corresponding to an improvement of the estimation of the wheel-rail contact forces. Fourth, an enhanced strategy to solve contact detection is envisaged so that the conformal contact can be tackled while ensuring the reliability of the multibody simulations. In this way, the simplification of the wheel profile is no longer required, making it possible to consider worn wheels, where different contact models could also be tested. Then, track irregularities must be included to determine the impact on the CPU time and on the noise generated in the calculation of the wheel-rail contact forces.

\section{Acknowledgements}

The first and second authors express their gratitude to the Portuguese Foundation for Science and Technology (Fundação para a Ciência e a Tecnologia) through the PhD grants SFRH/BD/96695/2013 and $\mathrm{PD} / \mathrm{BD} / 114154 / 2016$, respectively. This work was supported by FCT, through IDMEC, under LAETA, project UID/EMS/50022/2019”.

\section{References}

1. Pombo, J., Ambrósio, J., Silva, M.: A New Wheel-Rail Contact Model for Railway Dynamics. Veh. Syst. Dyn. 45, 165-189 (2007). doi:10.1080/00423110600996017

2. Weidemann, C.: State-of-the-Art Railway Vehicle Design with Multibody Simulation. J. Mech. Syst. Transp. Logist. 3, 12-26 (2010). doi:10.1299/jmtl.3.12

3. Polach, O., Böttcher, A., Vannucci, D., Sima, J., Schelle, H., Chollet, H., Götz, G., Garcia Prada, M., 
Nicklisch, D., Mazzola, L., Berg, M., Osman, M.: Validation of simulation models in the context of railway vehicle acceptance. Proc. Inst. Mech. Eng. Part F J. Rail Rapid Transit. 229, 729-754 (2015). doi:10.1177/0954409714554275

4. Magalhaes, H., Madeira, J.F.A., Ambrósio, J., Pombo, J.: Railway vehicle performance optimisation using virtual homologation. Veh. Syst. Dyn. 54, 1177-1207 (2016). doi:10.1080/00423114.2016.1196821

5. Magalhaes, H., Ambrósio, J., Pombo, J.: Railway vehicle modelling for the vehicle-track interaction compatibility analysis. Proc. Inst. Mech. Eng. Part K J. Multi-body Dyn. 230, 251-267 (2016). doi:10.1177/1464419315608275

6. BogojeviĆ, N., Lučanin, V.: The proposal of validation metrics for the assessment of the quality of simulations of the dynamic behaviour of railway vehicles. Proc. Inst. Mech. Eng. Part F J. Rail Rapid Transit. 230, 585-597 (2016). doi:10.1177/0954409714552700

7. Tao, G., Ren, D., Wang, L., Wen, Z., Jin, X.: Online prediction model for wheel wear considering track flexibility. Multibody Syst. Dyn. 44, 313-334 (2018). doi:10.1007/s11044-018-09633-5

8. Spangenberg, U., Frohling, R.D., Els, P.S.: Influence of wheel and rail profile shape on the initiation of rolling contact fatigue cracks at high axle loads. Veh. Syst. Dyn. 54, 638-652 (2016). doi:10.1080/00423114.2016.1150496

9. Ignesti, M., Innocenti, A., Marini, L., Meli, E., Rindi, A.: Development of a model for the simultaneous analysis of wheel and rail wear in railway systems. Multibody Syst. Dyn. 31, 191-240 (2014). doi:10.1016/j.wear.2014.10.008

10. Pombo, J., Ambrósio, J., Pereira, M., Lewis, R., Dwyer-Joyce, R., Ariaudo, C., Kuka, N.: Development of a Wear Prediction Tool for Steel Railway Wheels Using Three Alternative Wear Functions. Wear. 271, 238-245 (2011). doi:10.1016/j.wear.2010.10.072

11. Pombo, J., Ambrósio, J., Pereira, M., Lewis, R., Dwyer-Joyce, R., Ariaudo, C., Kuka, N.: A Study on Wear Evaluation of Railway Wheels based on Multibody Dynamics and Wear Computation. Multibody Syst. Dyn. 24, 347-366 (2010). doi:10.1007/s11044-010-9217-8

12. Six, K., Meierhofer, A., Trummer, G., Marte, C., Müller, G., Luber, B., Dietmaier, P., Rosenberger, M.: Classification and Consideration of Plasticity Phenomena in Wheel-Rail Contact Modelling. Int. J. Railw. Technol. 5, 55-77 (2016). doi:10.4203/ijrt.5.3.3.

13. Meymand, S.Z., Keylin, A., Ahmadian, M.: A survey of wheel-rail contact models for rail vehicles. Veh. Syst. Dyn. 54, 386-428 (2016). doi:10.1080/00423114.2015.1137956

14. Knothe, K., Böhm: History of Stability of Railway and Road Vehicles. Veh. Syst. Dyn. 31, 283-323 (2010). doi:10.1076/vesd.31.5.283.8362

15. Enblom, R.: Deterioration mechanisms in the wheel-rail interface with focus on wear prediction: a literature review. Veh. Syst. Dyn. 47, 661-700 (2009). doi:10.1080/00423110802331559

16. Sugiyama, H., Araki, K., Suda, Y.: On-line and off-line wheel/rail contact algorithm in the analysis of multibody railroad vehicle systems. J. Mech. Sci. Technol. 23, 991-996 (2009). doi:10.1007/s12206-009$0327-2$

17. Piotrowski, J., Chollet, H.: Wheel-rail contact models for vehicle system dynamics including multi-point contact. Veh. Syst. Dyn. 43, 455-483 (2005). doi:10.1080/00423110500141144

18. Elkins, J.A.: Prediction of Wheel/Rail Interaction: The State-of-the-Art. Veh. Syst. Dyn. 20, 1-27 (1992). doi:10.1080/00423119208969385

19. Alonso, A., Guiral, A., Giménez, J.G.: Wheel Rail Contact: Theoretical and Experimental Analysis. Int. J. Railw. Technol. 2, 15-32 (2013). doi:10.4203/ijrt.2.4.2

20. Piotrowski, J., Liu, B., Bruni, S.: The Kalker book of tables for non-Hertzian contact of wheel and rail. Veh. Syst. Dyn. 55, 875-901 (2017). doi:10.1080/00423114.2017.1291980 
21. Piotrowski, J., Bruni, S., Liu, B., Di Gialleonardo, E.: A fast method for determination of creep forces in non-Hertzian contact of wheel and rail based on a book of tables. Multibody Syst. Dyn. 45, 169-184 (2019). doi:10.1007/s11044-018-09635-3

22. Sichani, M.S., Enblom, R., Berg, M.: Non-Elliptic Wheel-Rail Contact Modelling in Vehicle Dynamics Simulation. Int. J. Railw. Technol. 3, 77-96 (2014). doi:10.4203/ijrt.3.3.5

23. Sh. Sichani, M., Enblom, R., Berg, M.: A novel method to model wheel-rail normal contact in vehicle dynamics simulation. Veh. Syst. Dyn. 52, 1752-1764 (2014). doi:10.1080/00423114.2014.961932

24. Sun, Y., Zhai, W., Guo, Y.: A robust non-Hertzian contact method for wheel-rail normal contact analysis. Veh. Syst. Dyn. 56, 1899-1921 (2018). doi:10.1080/00423114.2018.1439587

25. Liu, B., Bruni, S., Vollebregt, E.: A non-Hertzian method for solving wheel-rail normal contact problem taking into account the effect of yaw. Veh. Syst. Dyn. 54, 1226-1246 (2016). doi:10.1080/00423114.2016.1196823

26. Nikravesh, P.E.: Computer-Aided Analysis of Mechanical Systems. Prentice-Hall, Englewood Cliffs, New Jersey (1988)

27. Haug, E.: Computer Aided Kinematics and Dynamics of Mechanical Systems. Allyn and Bacon, Boston, Massachussetts (1989)

28. Pombo, J., Ambrósio, J.: Application of a Wheel-Rail Contact Model to Railway Dynamics in Small Radius Curved Tracks. Multibody Syst. Dyn. 19, 91-114 (2008). doi:10.1007/s11044-007-9094-y

29. Shabana, A.A., Zaazaa, K.E., Escalona, J.L., Sany, J.R.: Development of elastic force model for wheel/rail contact problems. J. Sound Vib. 269, 295-325 (2004). doi:10.1016/S0022-460X(03)00074-9

30. Sugiyama, H., Sekiguchi, T., Matsumura, R., Yamashita, S., Suda, Y.: Wheel/rail contact dynamics in turnout negotiations with combined nodal and non-conformal contact approach. Multibody Syst. Dyn. 27, 55-74 (2012). doi:10.1007/s11044-010-9215-x

31. Meli, E., Ridolfi, A.: An innovative wheel-rail contact model for railway vehicles under degraded adhesion conditions. Multibody Syst. Dyn. 33, 285-313 (2013). doi:10.1007/s11044-013-9405-4

32. Malvezzi, M., Meli, E., Falomi, S., Rindi, A.: Determination of wheel-rail contact points with semianalytic methods. Multibody Syst. Dyn. 20, 327-358 (2008). doi:10.1007/s11044-008-9123-5

33. Zaazaa, K.E., Schwab, A.L.: Review of Joost Kalker's wheel-rail contact theories and their implementation in multibody codes. In: Proceedings of the ASME 2009 International Design Engineering Technical Conference \& Computers and Information in Engineering Conference. pp. 1889$1990(2009)$

34. Marquis, B., Pascal, J.P.: Report on a railway Benchmark simulating a single wheelset without friction impacting a rigid track. Veh. Syst. Dyn. 46, 93-116 (2008). doi:10.1080/00423110701506905

35. Shackleton, P., Iwnicki, S.: Comparison of wheel-rail contact codes for railway vehicle simulation: an introduction to the Manchester Contact Benchmark and initial results. Veh. Syst. Dyn. 46, 129-149 (2008). doi:10.1080/00423110701790749

36. Bruni, S., Vinolas, J., Berg, M., Polach, O., Stichel, S.: Modelling of suspension components in a rail vehicle dynamics context. Veh. Syst. Dyn. 49, 1021-1072 (2011). doi:10.1080/00423114.2011.586430

37. Eickhoff, B.M., Evans, J.R., Minnis, A.J.: A Review of Modelling Methods for Railway Vehicle Suspension Components. Veh. Syst. Dyn. 24, 469-496 (1995). doi:10.1080/00423119508969105

38. Alfi, S., Bruni, S., Mazzola, L.: Impact of suspension component modelling on the accuracy of rail vehicle dynamics simulation. In: Procedings of the 11th Mini conference on Vehicle System Dynamics, Identification and Anomalies, Budapest, Hungary (2008)

39. Pombo, J., Ambrósio, J.: An Alternative Method to Include Track Irregularities in Railway Vehicle 
Dynamic Analyses. Nonlinear Dyn. 68, 161-176 (2012). doi:10.1007/s11071-011-0212-2

40. Ambrósio, J., Antunes, P., Pombo, J.J., Pombo, J.J.: On the requirements of interpolating polynomials for path motion constraints. Mech. Mach. Sci. 26, 179-197 (2015). doi:10.1007/978-3-319-10723-3_19

41. Bezin, Y., Funfschilling, C., Kraft, S., Mazzola, L.: Virtual testing environment tools for railway vehicle certification. Proc. Inst. Mech. Eng. Part F J. Rail Rapid Transit. 229, 755-769 (2015). doi:10.1177/0954409715587596

42. Antunes, P., Magalhaes, H., Ambrosio, J., Pombo, J., Costa, J.: A co-simulation approach to the railwheel contact with flexible railways. Multibody Syst. Dyn. 45, 245-272 (2019). doi:10.1007/s11044018-09646-0

43. Wu, Q., Sun, Y., Spiryagin, M., Cole, C.: Parallel Co-Simulation Method for Railway Vehicle-Track Dynamics. J. Comput. Nonlinear Dyn. 13, 041004 (2018). doi:10.1115/1.4039310

44. Costa, J., Antunes, P., Magalhaes, H., Ambrósio, J., Pombo, J.: Development of flexible track models for railway vehicle dynamics applications. Proc. Third Int. Conf. Railw. Technol. Res. Dev. Maintenance". 110, (2016). doi:10.4203/ccp.110.98

45. Di Gialleonardo, E., Braghin, F., Bruni, S.: The influence of track modelling options on the simulation of rail vehicle dynamics. J. Sound Vib. 331, 4246-4258 (2012). doi:10.1016/j.jsv.2012.04.024

46. Shabana, A.A., Tobaa, M., Sugiyama, H., Zaazaa, K.E.: On the computer formulations of the wheel/rail contact problem. Nonlinear Dyn. 40, 169-193 (2005). doi:10.1007/s11071-005-5200-y

47. Sugiyama, H., Suda, Y.: On the Contact Search Algorithms for Wheel/Rail Contact Problems. J. Comput. Nonlinear Dyn. 4, 41001 (2009). doi:10.1115/1.3187211

48. Escalona, J.L., Aceituno, J.F.: Multibody simulation of railway vehicles with contact lookup tables. Int. J. Mech. Sci. 155, 571-582 (2019). doi:10.1016/j.ijmecsci.2018.01.020

49. Matsumura, R., Sugiyama, H., Suda, Y.: Analysis of Vehicle/Turnout Interactions of Railroad Vehicles Using Multiple Contact Tables. J. Syst. Des. Dyn. 5, 450-460 (2011). doi:10.1299/jsdd.5.450

50. Falomi, S., Malvezzi, M., Meli, E.: Multibody modeling of railway vehicles: Innovative algorithms for the detection of wheel-rail contact points. Wear. 271, 453-461 (2011). doi:10.1016/j.wear.2010.10.039

51. Bozzone, M., Pennestrì, E., Salvini, P.: A lookup table-based method for wheel-rail contact analysis. Proc. Inst. Mech. Eng. Part K J. Multi-body Dyn. 225, 127-138 (2011). doi:10.1177/2041306810394721

52. Bozzone, M., Pennestrì, E., Salvini, P.: Dynamic analysis of a bogie for hunting detection through a simplified wheel-rail contact model. Multibody Syst. Dyn. 25, 429-460 (2011). doi:10.1007/s11044-0109233-8

53. Pascal, J.P., Jourdan, F.: The "Rigid-Multi-Hertzian Method" as Applied to Conformal Contacts. In: Volume 5: 6th International Conference on Multibody Systems, Nonlinear Dynamics, and Control, Parts A, B, and C. pp. 1811-1825. ASME (2007)

54. Blanco-Lorenzo, J., Santamaria, J., Vadillo, E.G., Correa, N.: On the influence of conformity on wheelrail rolling contact mechanics. Tribol. Int. 103, 647-667 (2016). doi:10.1016/j.triboint.2016.07.017

55. Vollebregt, E., Segal, G.: Solving conformal wheel-rail rolling contact problems. Veh. Syst. Dyn. 52, 455-468 (2014). doi:10.1080/00423114.2014.906634

56. Vollebregt, E.A.H.: Conformal contact: corrections and new results. Veh. Syst. Dyn. 56, 1622-1632 (2018). doi:10.1080/00423114.2018.1424917

57. Marques, F., Magalhaes, H., Pombo, J., Flores, P., Ambrosio, J.: Development of a new wheel-rail contact model for multibody simulations. In: Proceedings of the Fourth International Conference on Railway Technology: Research, Development and Maintenance". , Sitges, Spain (2018) 
58. Kalker, J.J.: Three-Dimensional Elastic Bodies in Rolling Contact. Kluwer Academic Publishers, Dordrecht, The Netherlands (1990)

59. Piotrowski, J., Kik, W.: A simplified model of wheel/rail contact mechanics for non-Hertzian problems and its application in rail vehicle dynamic simulations. Veh. Syst. Dyn. 46, 27-48 (2008). doi:10.1080/00423110701586444

60. Ayasse, J.B., Chollet, H.: Determination of the wheel rail contact patch in semi-Hertzian conditions. Veh. Syst. Dyn. 43, 161-172 (2005). doi:10.1080/00423110412331327193

61. Quost, X., Sebes, M., Eddhahak, A., Ayasse, J., Chollet, H., Gautier, P., Thouverez, F.: Assessment of a Semi-Hertzian Method for Determination of Wheel-Rail Contact Patch. Veh. Syst. Dyn. 44, 789-814 (2006). doi:10.1080/00423110600677948

62. Lankarani, H.M., Nikravesh, P.E.: Continuous Contact Force Models for Impact Analysis in Multibody Systems. Nonlinear Dyn. 5, 193-207 (1994)

63. Lankarani, H.M., Nikravesh, P.E.: A Contact Force Model with Hysteresis Damping for Impact Analysis of Multibody Systems. AMSE J. Mech. Des. 112, 369-376 (1990)

64. Vollebregt, E.A.H., Iwnicki, S.D., Xie, G., Shackleton, P.: Assessing the accuracy of different simplified frictional rolling contact algorithms. Veh. Syst. Dyn. 50, 1-17 (2012). doi:10.1080/00423114.2011.552618

65. Kalker, J.J.: On the Rolling Contact of Two Elastic Bodies in the Presence of Dry Friction, (1967)

66. Johnson, K.L., Vermeulen, P.J.: Contact of Non-Spherical Bodies Transmitting Tangential Forces. J. Appl. Mech. 31, 338-340 (1964). doi:10.1115/1.3629610

67. Shen, Z.Y., Hedrick, J.K., Elkins, J.A.: A Comparison of Alternative Creep Force Models for Rail Vehicle Dynamic Analysis. Veh. Syst. Dyn. 12, 79-83 (1983). doi:10.1080/00423118308968725

68. Kalker, J.J.: A Fast Algorithm for the Simplified Theory of Rolling-Contact. Veh. Syst. Dyn. 11, 1-13 (1982). doi:10.1080/00423118208968684

69. Polach, O.: A Fast Wheel-Rail Forces Calculation Computer Code. Veh. Syst. Dyn. 33, 728-739 (1999). doi:10.1080/00423114.2013.826370

70. Kalker, J.J.: Book of Tables for the Hertzian Creep-Force Law. Delft University of Technology, Delft, The Netherlands (1996)

71. Sh. Sichani, M., Enblom, R., Berg, M.: An alternative to FASTSIM for tangential solution of the wheelrail contact. Veh. Syst. Dyn. 54, 748-764 (2016). doi:10.1080/00423114.2016.1156135

72. Marques, F., Magalhaes, H., Liu, B., Pombo, J., Flores, P., Ambrósio, J., Piotrowski, J., Bruni, S.: On the generation of an enhanced lookup table for wheel-rail contact models. In: The 11th International Conference on Contact Mechanics and Wear of Rail/Wheel Systems. , Delft, The Netherlands (2018)

73. Vollebregt, E.A.H.: Comments on 'the Kalker book of tables for non-Hertzian contact of wheel and rail.' Veh. Syst. Dyn. 56, 1451-1459 (2018). doi:10.1080/00423114.2017.1421767

74. Piotrowski, J., Bruni, S., Liu, B.: Reply to comments on 'The Kalker book of tables for non-Hertzian contact of wheel and rail' by E. A. H. Vollebregt. Veh. Syst. Dyn. 56, 1460-1459 (2018). doi:10.1080/00423114.2018.1437274

75. Magalhaes, H., Ambrósio, J., Pombo, J.: Simulation of a Railway Vehicle Running in a Mountainous Track at a Prescribed Speed. Proc. Third Int. Conf. Railw. Technol. Res. Dev. Maintenance". (2016). doi:doi: $10.4203 /$ ccp. 110.100

76. Magalhaes, H., Pombo, J., Ambrosio, J., Madeira, J.F.A.: Rail vehicle design optimization for operation in a mountainous railway track. Innov. Infrastruct. Solut. 2, 1-6 (2017). doi:10.1007/s41062-017-0088-1 
77. Ambrósio, J., Pombo, J., Antunes, P., Pereira, M.: PantoCat statement of method. Veh. Syst. Dyn. 53, 314-328 (2015). doi:10.1080/00423114.2014.969283

78. Ambrósio, J., Pombo, J.: A unified formulation for mechanical joints with and without clearances/bushings and/or stops in the framework of multibody systems. Multibody Syst. Dyn. 42, $317-$ 345 (2018). doi:10.1007/s11044-018-9613-z

79. Goldsmith, W.: Impact - The Theory and Physical Behaviour of Colliding Solids. Edward Arnold LTD, London, United Kingdom (1960)

80. Hunt, K., Crossley, F.: Coefficient of restitution interpreted as damping in vibroimpact. J. Appl. Mech. 7, 440-445 (1975)

81. Pombo, J., Ambrósio, J.: A Computational Efficient General Wheel-Rail Contact Detection Method. J. Mech. Sci. Technol. Sep. Vol. KSME Int. J. 19, 411-421 (2005)

82. Vollebregt, E.: User guide for CONTACT, Version v17.1, (2017) 